Univerza

$v$ Ljubljani

Fakulteta

za gradbeništvo

in geodezijo

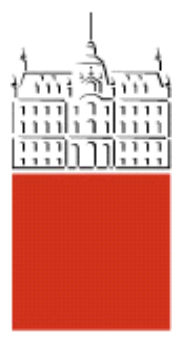

Jamova cesta 2

1000 Ljubljana, Slovenija

http://www3.fgg.uni-lj.si/

\section{DRUGG - Digitalni repozitorij UL FGG} http://drugg.fgg.uni-lj.si/

V zbirki je izvirna različica izdajatelja.

Prosimo, da se pri navajanju sklicujete na bibliografske podatke, kot je navedeno:
University

of Ljubljana

Faculty of

Civil and Geodetic

Engineering

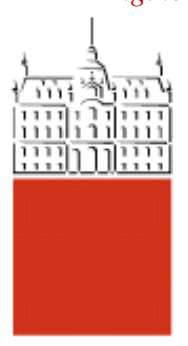

Jamova cesta 2

SI - 1000 Ljubljana, Slovenia

http://www3.fgg.uni-lj.si/en/

DRUGG - The Digital Repository http://drugg.fgg.uni-lj.si/

This is a publisher's version PDF file.

When citing, please refer to the publisher's bibliographic information as follows:

Klopčič, J., Logar, J. 2014. Effect of relative orientation of anisotropy planes to tunnel axis on the magnitude of tunnelling displacements. International journal of rock mechanics and mining sciences 71: $235-248$.

http://www.sciencedirect.com/science/article/pii/S1365160914001865 


\title{
Effect of relative orientation of anisotropy planes to tunnel axis on the magnitude of tunnelling displacements
}

\author{
Jure Klopčič ${ }^{a}$ \\ aUniversity of Ljubljana, Faculty of Civil and Geodetic Engineering, Jamova c. 2, 1000 Ljubljana, \\ Slovenia, jure.klopcic@fgg.uni-li.si \\ Janko Logar ${ }^{\mathrm{b}}$ (corresponding author) \\ ${ }^{b}$ University of Ljubljana, Faculty of Civil and Geodetic Engineering, Jamova c. 2, 1000 Ljubljana, \\ Slovenia, janko.logar@fgg.uni-lj.si, phone: +386 41654169
}

\begin{abstract}
When analysing the measured displacements at the Trojane tunnel (Slovenia), excavated in soft foliated rock mass, some interesting deformation patterns were observed, especially large surface settlements that appeared despite quick ring closure, stiff lining and consequently small tunnel lining displacement. It soon became clear that most of these phenomena are the consequences of highly anisotropic nature of the soft foliated rock mass. A vast number of numerical analyses were performed, varying dip direction and dip angle of the anisotropy planes as well as strength and stiffness parameters of the rock mass (degree of rock mass anisotropy). The share of displacements that occur ahead of the tunnel face and the extent of influential zone ahead of the tunnel face are presented as primary results. Further on, the effect of tunnelling with and against the anisotropy planes in the same material is presented. The effect of overburden above the tunnel and the influence of the orientation of anisotropy plane on the surface settlements were investigated. To verify the obtained numerical results, comparisons to the measurements inside and above the Trojane tunnel were made.
\end{abstract}

Keywords: tunnelling, anisotropic rock, displacement

\section{INTRODUCTION}

Anisotropy of the rock mass refers to its direction-dependent properties that strongly influence the stress re-distribution and displacements. Usually it is associated with weak planes in rock mass structure (foliation, bedding planes, faults, joints) and leads to lower stiffness in the direction normal to the discontinuities and higher stiffness in the direction parallel to the rock mass structure (Wyllie [1]). The response of the underground structure in case of anisotropic rock conditions thus strongly depends on strength properties and relative orientation of discontinuities to an opening (Wittke [2]; Solak [3]). Experience from some projects in foliated rock mass also show significant dependence of costs, displacement magnitudes, construction time and quantity of primary support needed for successful tunnelling on different relative orientations of foliation with regard to the tunnel tube (Huber et al [4]). 
In anisotropic rock mass, the resulting magnitude and orientation of the displacement vector are the combination of normal displacement that would occur in isotropic rock mass and additionally from the shear displacements along the discontinuities and from dilatation of the discontinuities. Knowledge of how the tunnel response changes with the relative orientation of the discontinuities is essential in order to properly understand and interpret monitoring results in anisotropic rock mass conditions. A general behaviour can be investigated using two-dimensional numerical analyses solely in case where the strike of the discontinuities is parallel to the tunnel axis (Goricki et al [5]). In all other cases, the simplified 2D simulations cannot take into account the development of the displacements with approaching and receding tunnel face; thus, time consuming $3 D$ analyses are necessary. If the strength of the rock mass depends on small scale deformation behaviour, e.g. thin layered schist, a continuum model can adequately represent ground behaviour (Leitner et al [6]).

3D numerical analyses of the influence of elastic anisotropy on tunnel wall displacements performed by Tonon [7] showed that the foliation direction also affects displacements ahead of the face, if the plane of transverse isotropy does not strike parallel to the tunnel axis. Two different cases were analyzed: one with the planes of transverse isotropy dipping in the tunnel (referred to as tunnelling "against dip", as shown in Fig. 1) and the other with planes dipping in the excavation direction (referred to as tunnelling "with dip"). Analyses showed that when tunnelling with dip, over $60 \%$ of the total displacements occur before the section is excavated, while in the opposite case only less than $10 \%$. Tonon explained this phenomenon with stiffer rock mass parallel to the plane of anisotropy and more deformable perpendicular to it. When tunnelling with dip, the rock mass is more deformable towards the excavated part of the tunnel and it can freely expand. In the opposite case almost no displacements can occur, since the rock mass is more deformable in the non-excavated part of the tunnel and the majority of the convergences occur after the excavation of a section.

As the tunnel circumference converges inwards due to stress redistribution, the overexcavation of the profile is required with regard to the expected deformation. Assessment of the magnitude of these deformations is one of the most demanding tasks of a geotechnical engineer in the underground construction process since it is influenced by several factors. However, a proper procedure for a site engineer would be to evaluate the displacement monitoring data and to determine the amount of overexcavation according to the expected geological conditions and displacements. There are only a few methods available for such task. 3D numerical analyses are time consuming and therefore not suitable to use on a day-to-day basis. Additionally, some simplifications are applied: complex geological structures cannot be modelled in detail, input parameters and primary stress state are only known to a certain extent. Even more simplifications of the stress and rock mass conditions with limitations to two-dimensional and time independent problems are involved in analytical methods (Sellner [8]). To overcome these deficiencies a simple but accurate method was developed by Sulem et al [9], extended by Barlow [10] and further modified by Sellner [8]. The proposed method focuses solely on radial displacements, since they are the most easily obtainable and universally measured and describe the displacement behaviour of the rock mass and support in radial direction as a function of excavation advance and time dependent response of the rock mass (Barlow [10]). Semi-empirical function of hyperbolic shape is fitted to the displacement measurements by adjusting what is called 
function's parameters. These parameters describe the response of the rock mass and support, taking into account the sequentially staged construction. The magnitudes of two basic parameters of displacement function, which are normally taken as constants for isotropic rock masses, are shown (by means of numerical analyses) to vary considerably for anisotropic rock mass depending on relative orientation of tunnel excavation with respect to dip and dip direction of planes of anisotropy.

The validity of conclusions based on numerical work is checked on the case history of the Trojane tunnel, excavated in soft densely foliated claystone and siltstone.

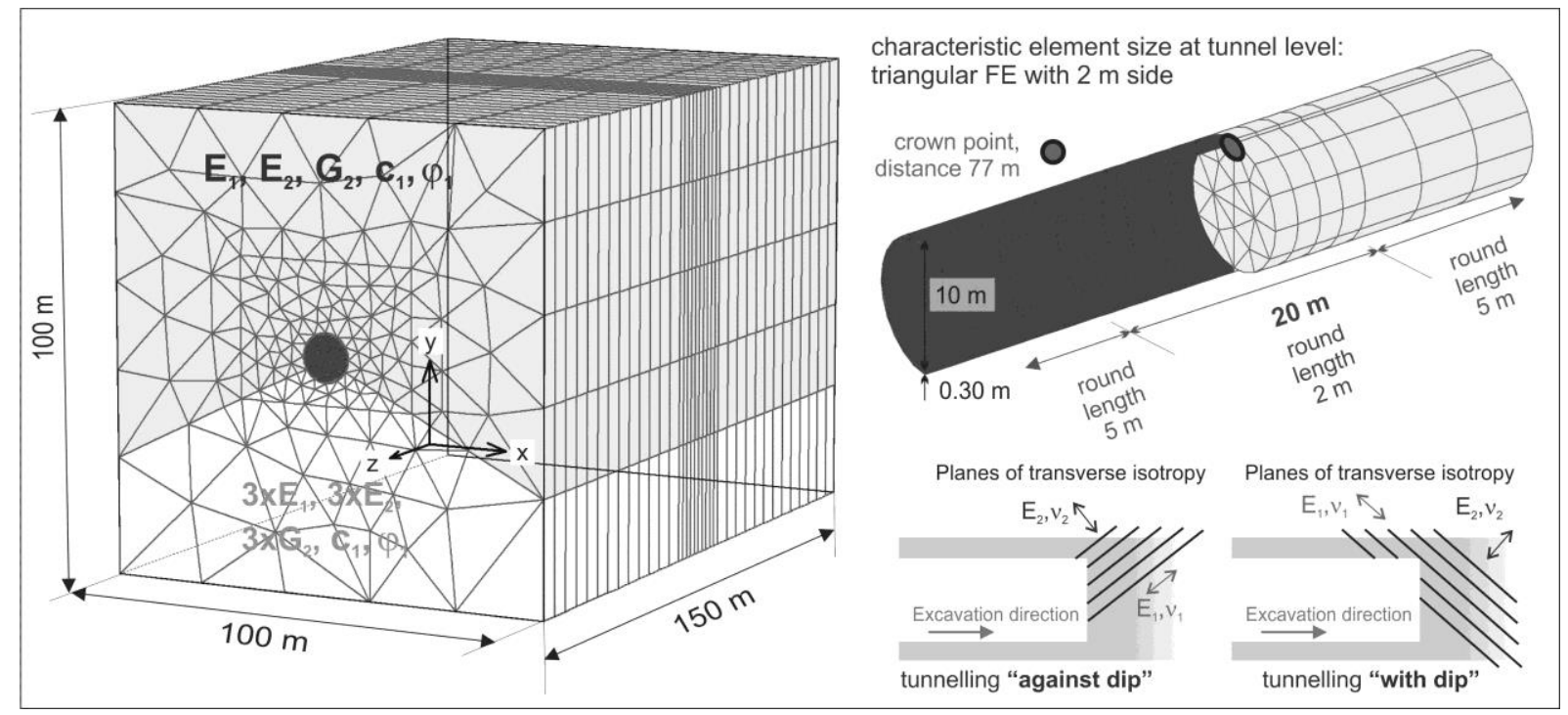

Fig. 1. Numerical model

\section{METHODS}

\subsection{DISPLACEMENT FUNCTION (CONVERGENCE EQUATION)}

The original proposal for the convergence equation was given by Guenot et al [11]. This analytical function describes the displacements within a cross section of a circular tunnel with full face excavation without the support installation. These displacements are caused by face advance effect and time-dependent effects of the rock mass. In order to overcome the limitations of the convergence equation, Barlow [10] extended the displacement function for more realistic description of the conditions during tunnelling, especially in soft rock mass. Barlow added to the displacement function a part of the curve that describes displacements occurring ahead of the face to account for the sequential excavation. Displacements related to individual excavation steps were simply superposed. Further on, Barlow introduced the influence of support by adding one additional parameter to the displacement function. Further modifications of the displacement function were introduced by Sellner [8]. The final displacement function used in the scope of this paper is expressed by the following three equations: Eq. (1) gives the displacement that occurs ahead of the face, Eq. (2) the displacement that occurs between the excavation and the installation of support and Eq. (3) the displacement that occurs after the installation of support.

$C(x, t)=\left[Q_{1} \cdot C_{p f}(x)-Q_{k} \cdot P_{k}^{+}(x)\right] \cdot\left[C_{x \infty}+A \cdot C_{2}(t)\right]$ 


$$
\begin{aligned}
& C(x, t)=\left[Q_{1}+Q_{2} \cdot C_{1}(x)-Q_{k} \cdot P_{k}^{+}(x)\right] \cdot\left[C_{x \infty}+A \cdot C_{2}(t)\right] \\
& C(x, t)=\frac{\left[Q_{1}+Q_{2} \cdot C_{1}(x)+K \cdot C_{S}-Q_{k} \cdot P_{k}^{-}(x)\right]}{\left[1+K \cdot\left(C_{x \infty}+A \cdot C_{2}(t)\right)\right]} \cdot\left[C_{x \infty}+A \cdot C_{2}(t)\right](3) \\
& C_{1}(x)=\left[1-\left(\frac{x}{X+x}\right)^{2}\right] \\
& C_{2}(t)=\left[1-\left(\frac{T}{T+t}\right)^{0.3}\right] \\
& C_{p f}=\left[\frac{X}{X+\left(x_{f}-x\right)}\right]^{1.2}
\end{aligned}
$$

Eq. (4) represents time independent function or loading function, $x$ distance between observed cross section and excavation face and $X$ curve fitting parameter describing the shape of $C_{1}(x)$. High $X$ values indicate that the face advance influences displacements even when far away from the measuring section (Schubert et al [12]). Eq. (5) defines time dependent function, where $t$ denotes the time elapsed between excavation and observation time and $T$ curve fitting parameter describing the shape of $C_{2}(t)$. Low $T$ values indicate that the displacements vanish shortly after excavation (Schubert et al [12]). $C_{x \infty}$ and $A$ denote curve fitting parameters describing ultimate time independent displacement and ultimate time dependent displacement, respectively. $Q_{1}$ is the proportion of the total stress change due to the tunnel excavation that occurs ahead of the face and $Q_{2}$ the proportion of the total stress change that occurs after the excavation face passes the monitored cross section $\left(Q_{1}+Q_{2}\right.$ =1). $Q_{k} \cdot P_{k^{+}}(x)$ and $Q_{k} \cdot P_{k}(x)$ are functions that distribute the effect of the support installation on the displacements ahead and behind the face, respectively. $K$ is the parameter of the support and $C_{S}$ the displacement at the time of support installation. Finally, the loading function ahead of the face is defined with Eq. (6) where $x_{f}$ denotes the length of the influential area ahead of the excavation face.

A simple algorithm that enables fast and reliable assessment of the stabilization process and the displacement magnitude in the observed measuring section (Sellner [8]) is a major advantage of using the displacement function if compared to other methods described in the introduction. Unlike the analytical methods, the displacement function takes account of time effects and 3D effects of the tunnel excavation. Additionally, the displacement function is a much more time-effective method than the numerical calculations and it does not require a large number of parameters, the determination of which would demand a lot of costly and time-consuming laboratory tests. These advantages make the displacement function suitable for the use on a day-to-day basis at construction sites (Sellner [8]). While part 3 of the displacement function is very well defined by fitting the curve to the measured displacements, parts 1 and 2 are determined on the basis of numerical simulations and rely on the parameters that depend on the rock mass behaviour ahead of the tunnel face: $Q_{1}$ and $x_{f}$. Barlow found 
out that value $Q_{1}$ amounts to 0.27 for elastic conditions and that it increases for non-elastic conditions and with the increasing extent of the plastic zone (it can reach the value of 0.6 for plastic zone of two times the tunnel radius). Analysis of the monitoring results of vertical extensometer, horizontal inclinometer and 3D displacement measurements (Klopčič [13]) indicated that the displacements ahead of the face can amount to up to $75 \%$ of the total displacement of the measurement point.

\subsection{D NUMERICAL CALCULATIONS}

Due to the abovementioned observations of Tonon [7] and case history from the Trojane tunnel in Slovenia (see section 4) the influence of the relative discontinuity orientation and different ground conditions on parameters $Q_{1}$ and $X_{f}$, was thoroughly studied. A large number of 3D numerical calculations were performed using Plaxis $3 D$ Tunnel FE code, varying rock mass parameters and the relative orientation of the discontinuity planes to the tunnel axis. Anisotropic behaviour of the rock mass was modelled with the Plaxis' Jointed rock constitutive law (JR). Numerical model is presented in Fig. 1, material parameters in Tab. 1 and their variations in Tab. 2. A circular tunnel with a diameter of $10 \mathrm{~m}$ was analysed. $30 \mathrm{~cm}$ thick shotcrete lining was modelled by soil clusters using Mohr-Coulomb constitutive law (MC). Elastic modulus of $8 \mathrm{GPa}$ was used for the lining, thus incorporating the influence of young and cracked shotcrete when exposed to the loads of the surrounding rock mass.

Table 1. Material properties of shotcrete and rock mass

\begin{tabular}{|c|c|c|c|}
\hline & shotcrete & & rock mass \\
\hline Material model & Mohr-Coulomb (MC) & Material model & Jointed Rock (JR) \\
\hline$\gamma\left[\mathrm{kN} / \mathrm{m}^{3}\right]$ & 25 & $\gamma\left[\mathrm{kN} / \mathrm{m}^{3}\right]$ & 26.5 \\
\hline$E[\mathrm{GPa}]$ & 8 & $E_{1}[\mathrm{MPa}]$ & 600 \\
\hline $\mathrm{v}$ & 0.2 & $v_{1}=v_{2}$ & 0.25 \\
\hline$c[\mathrm{kPa}]$ & 5000 & $c_{1}[\mathrm{kPa}]$ & 30 \\
\hline$\varphi\left[^{\circ}\right]$ & 20 & $\varphi_{1}\left[^{\circ}\right]$ & 18 \\
\hline
\end{tabular}

The specific parameters of anisotropic Jointed rock material model have the following meaning: $E_{1}$ and $\nu_{1}$ are the Young's modulus and Poisson's ratio for rock as a continuum (parallel to the plane of anisotropy), respectively. Similarly $E_{2}, G_{2}$ and $v_{2}$ are Young's modulus, shear modulus and Poisson's ratio perpendicular to the plane of anisotropy, respectively. $\varphi_{1}$ is friction angle and $c_{1}$ cohesion, both along the plane of anisotropy.

The basic material parameters of the rock mass shown in Tab. 1 were derived on the basis of in-situ tests and back calculations of different projects in soft foliated rock mass of Carboniferous age (Likar [14], Likar \& Vukadin [15], Klopčič [13]) that was encountered during the Trojane tunnel construction.

Three dip directions were applied: (1) $0^{\circ}$ - strike perpendicular to the tunnel axis, (2) $45^{\circ}$ - strike at an angle of $45^{\circ}$ to the tunnel axis and (3) $90^{\circ}$ - strike parallel to the tunnel axis. For each of these three dip directions the dip was varied in range $\left[-90^{\circ}, 90^{\circ}\right]$ with a step of $15^{\circ}$. Further on, three different $E_{1}: E_{2}$ 
ratios and three different values of shear modulus $G_{2}$ were investigated, as shown in Tab. 2 (denotation $G$ is given to the isotropic value of shear modulus $G=E_{1} /\left(2\left(1+v_{1}\right)\right)$.

Table 2. List of parameters and their variations

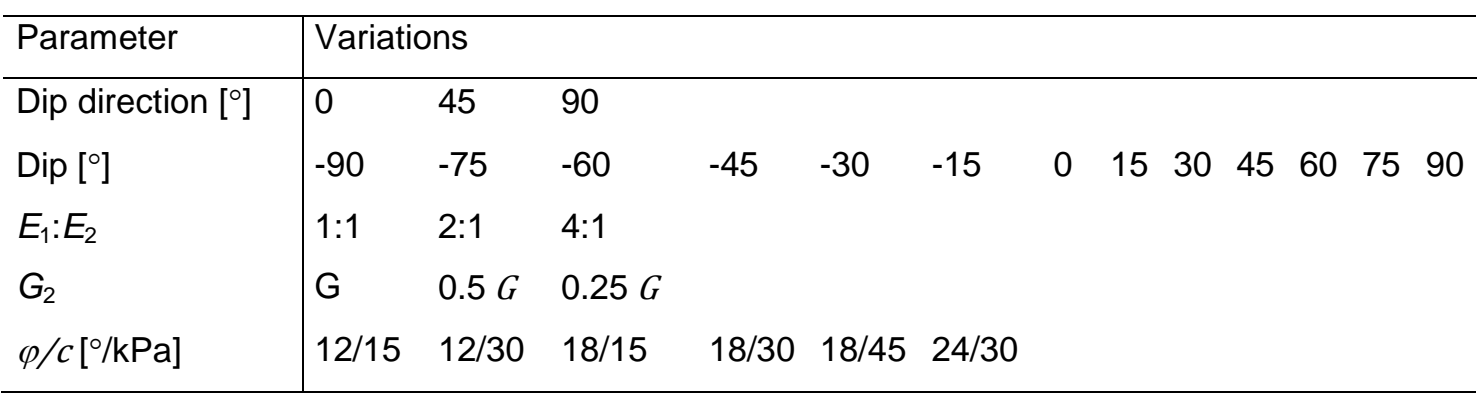

As a reference, calculations were performed also with elastic (EL) parameters $\left(E=E_{1}, v=v_{1}\right)$ and Hardening soil (HS) constitutive model $\left(E_{50}^{\mathrm{ref}}=E_{\mathrm{oed}}^{\mathrm{ref}}=E_{1}, E_{\mathrm{ur}}^{\mathrm{ref}}=3 E_{1}, c=c_{1}, \varphi=\varphi_{1}, m=0.5, E_{50}^{\mathrm{ref}}=\right.$ $\left.K_{50}^{\mathrm{NC}}=0.691, \nu_{\text {ur }}=0.2, p_{\text {ref }}=1050 \mathrm{kPa}\right)$. To reduce the unrealistic uplift, material with three times higher stiffness parameters was applied at the bottom of the numerical model for elastic and Jointed rock constitutive models (Fig. 1).

In the next stage of analysis the influence of variation of strength parameters was investigated for selected combinations of stiffness parameters and dips. In total more than 600 3D numerical calculations were performed within the presented parametric study.

A $150 \mathrm{~m}$ long model was used. The characteristic element size in the vicinity of the tunnel was $2 \mathrm{~m}$. The round length at both ends of the model was $5 \mathrm{~m}$, only the inner $20 \mathrm{~m}$ (where the tracked points were located) were excavated with an excavation step of $2 \mathrm{~m}$. The complete cross section of the circular tunnel was excavated at once and immediately supported by a $30 \mathrm{~cm}$ thick shotcrete lining.

\section{NUMERICAL RESULTS}

The vertical displacement of a crown point at station $z=77 \mathrm{~m}$ was tracked in all cases, divided in displacements occurring ahead and behind the tunnel face. From the results of numerical analyses, the key parameters of the displacement function were assessed and their variation with dip/dip direction and degree of anisotropy was analysed. In order to keep Figures 3 to 6 legible, only selected curves are presented and the range of results is shown by shaded area. For details see the thesis by Klopčič [13].

\subsection{Share of displacements occurring ahead of tunnel face}

Curves of parameter $Q_{1}$ (share of total displacement occurring ahead of face) for $G_{2}=0.5 G$ and the three $E_{1}: E_{2}$ ratios are shown for each of the three dip directions separately in Fig. 2 together with the results for elastic (EL) and hardening soil (HS) material. The shaded area shows the whole variation of results, including $G_{2}=0.25 G$ and $G_{2}=G$ which are not explicitly shown by separate curves. 


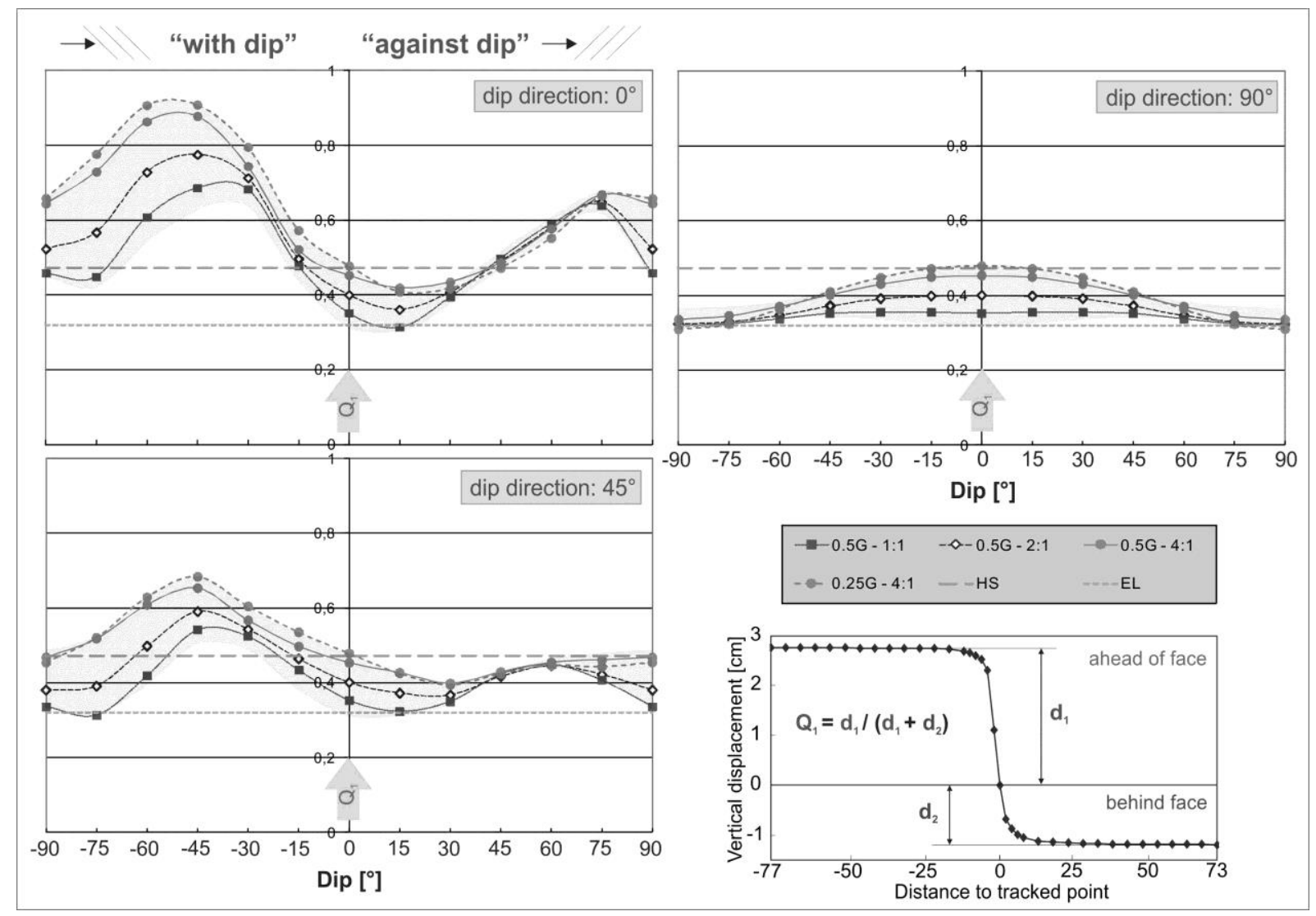

Fig. 2. Calculated share of displacements occurring ahead of face $\left(Q_{1}\right)$ for all combinations of dip directions, $E_{1}: E_{2}$ ratios, shear moduli and dip angles.

The variation of the $E_{1}: E_{2}$ ratio has more pronounced effect on the $Q_{1}$ value than the applied variation of shear modulus $G_{2}$.

Values of parameter $Q_{1}$ depend significantly on dip and dip direction. A large scatter of the $Q_{1}$ values can be observed when tunnelling with dip, especially for steeper discontinuity inclinations (dip angles $45^{\circ},-60^{\circ}$ and $-75^{\circ}$ ). On the other hand, the scatter is small for dip angles from $30^{\circ}$ to $75^{\circ}$ when tunnelling against dip and it reveals very limited dependence of the $Q_{1}$ value on the material parameters of the surrounding rock mass. For dip direction $90^{\circ}$ the $Q_{1}$ values depend less on dip.

The upper boundary of the shaded area when tunnelling with dip and the lower boundary when tunnelling against dip are both defined with a curve, calculated with the ratio $E_{1}: E_{2}=4: 1$ and shear modulus of $25 \%$ of isotropic $G_{2}$, while the lower boundary of the shaded area when tunnelling with dip and the upper boundary when tunnelling against dip are defined with a curve, calculated with the ratio $E_{1}: E_{2}=1: 1$ and isotropic shear modulus.

The maximum values of $Q_{1}$ amount to $0.91,0.68$ and 0.48 for dip directions $0^{\circ}, 45^{\circ}$ and $90^{\circ}$, respectively. The minimum values for all three dip directions are similar to the value obtained by elastic parameters (0.32), while $Q_{1}$ calculated with the Hardening soil constitutive model $(0.47)$ is close to the highest calculated $Q_{1}$ value (0.48) for the dip direction of $90^{\circ}$. 


\subsection{Influential length ahead of the excavation face}

Plots in Fig. 3 present the calculated influential length ahead of the excavation face, $x_{f}$. The beginning of the influential area was arbitrarily determined at $10 \%$ of the maximum displacement that occurs ahead of the face. Klopčič [13] found out that by using smaller share of displacement (3\%) for the definition of the beginning of the influential area, the results become too sensitive to iterative numerical procedure.

The influential length ahead of the excavation face was found to be in the range from 6 to $27 \mathrm{~m}$ ( 0.6 to 2.7 tunnel diameter). The largest range of values was obtained for dip direction $0^{\circ}$. The range of calculated $x_{f}$ values is similar for dip directions $45^{\circ}$ and $90^{\circ}$ (from 6 to $22 \mathrm{~m}$ ). It is interesting to note that the $x_{f}$ values are considerably higher for isotropic materials - elastic (EL) and especially hardening soil (HS).

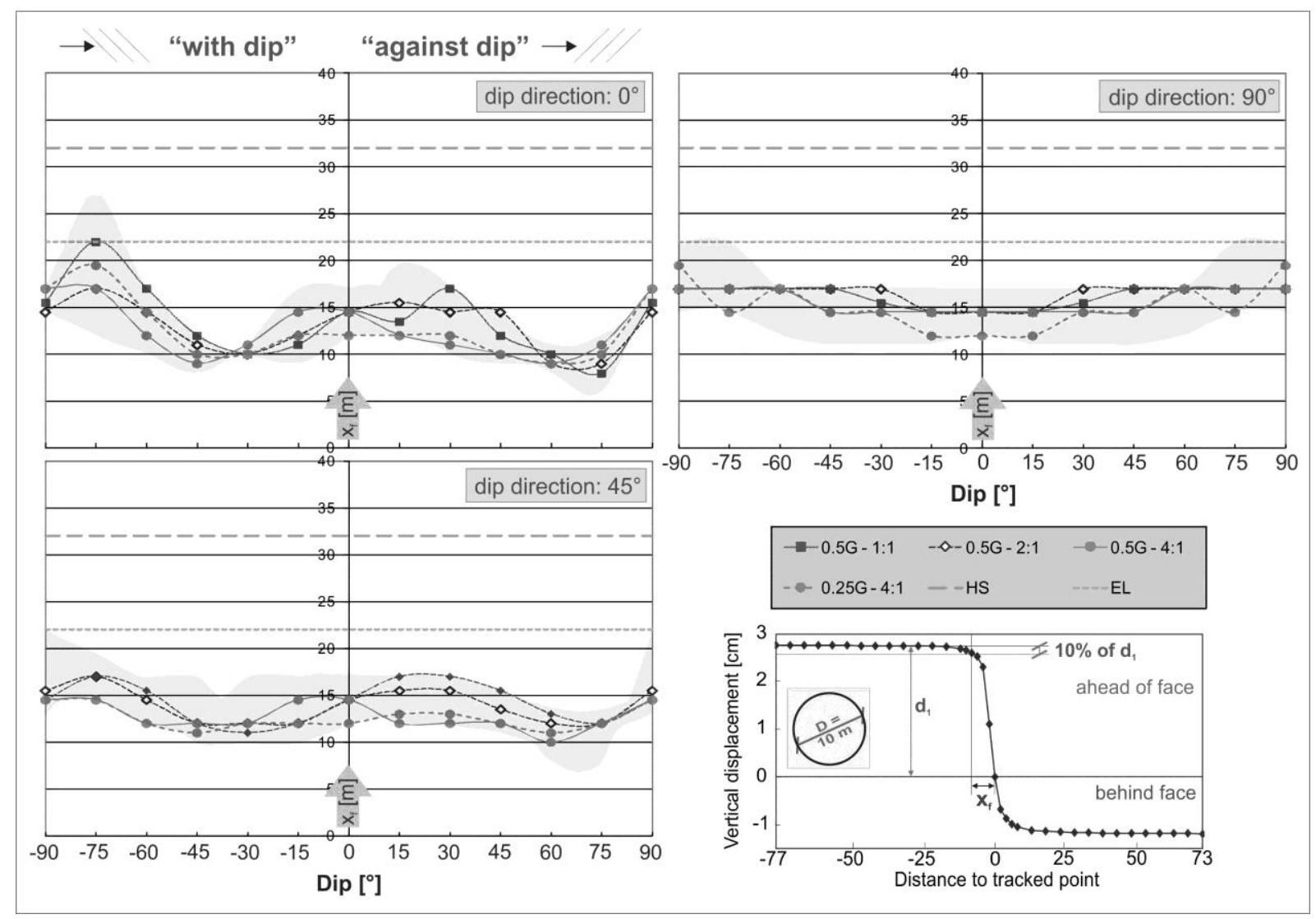

Fig. 3. Calculated parameter $x_{f}$ for all combinations of dip directions, $E_{1}: E_{2}$ ratios, shear moduli and dip angles.

\subsection{Magnitude of total displacements}

The total displacement magnitude of the tunnel crown also varies for different dip angles and directions, even though calculated with the same material properties. For comparison, the curves of total displacements were normalized to the curve at $0^{\circ} / 0^{\circ}$, which is common to all dip directions. Results of normalized total displacements (hereinafter denoted as $|d|$ ) are presented in Fig. 4. The 
total normalized displacements for different dip directions, dip angles and $E_{1}: E_{2}$ ratios were calculated in the range from $50 \%$ to $120 \%$ of the total displacement at the discontinuity orientation $0 \% 0^{\circ}$. The magnitude of normalized total displacements is strongly dependent on the $E_{1}: E_{2}$ ratio and the dip angle and less on the shear modulus.

The highlighted areas of the calculated results are symmetric with regard to the vertical axis for dip direction $90^{\circ}$ and slightly asymmetric for dip direction $45^{\circ}$. The values of total normalized displacements are not symmetric with regard to the vertical axis for dip direction $0^{\circ}$. This shows the important influence of the direction of tunnel excavation in anisotropic rock on the magnitude of rock mass displacements.

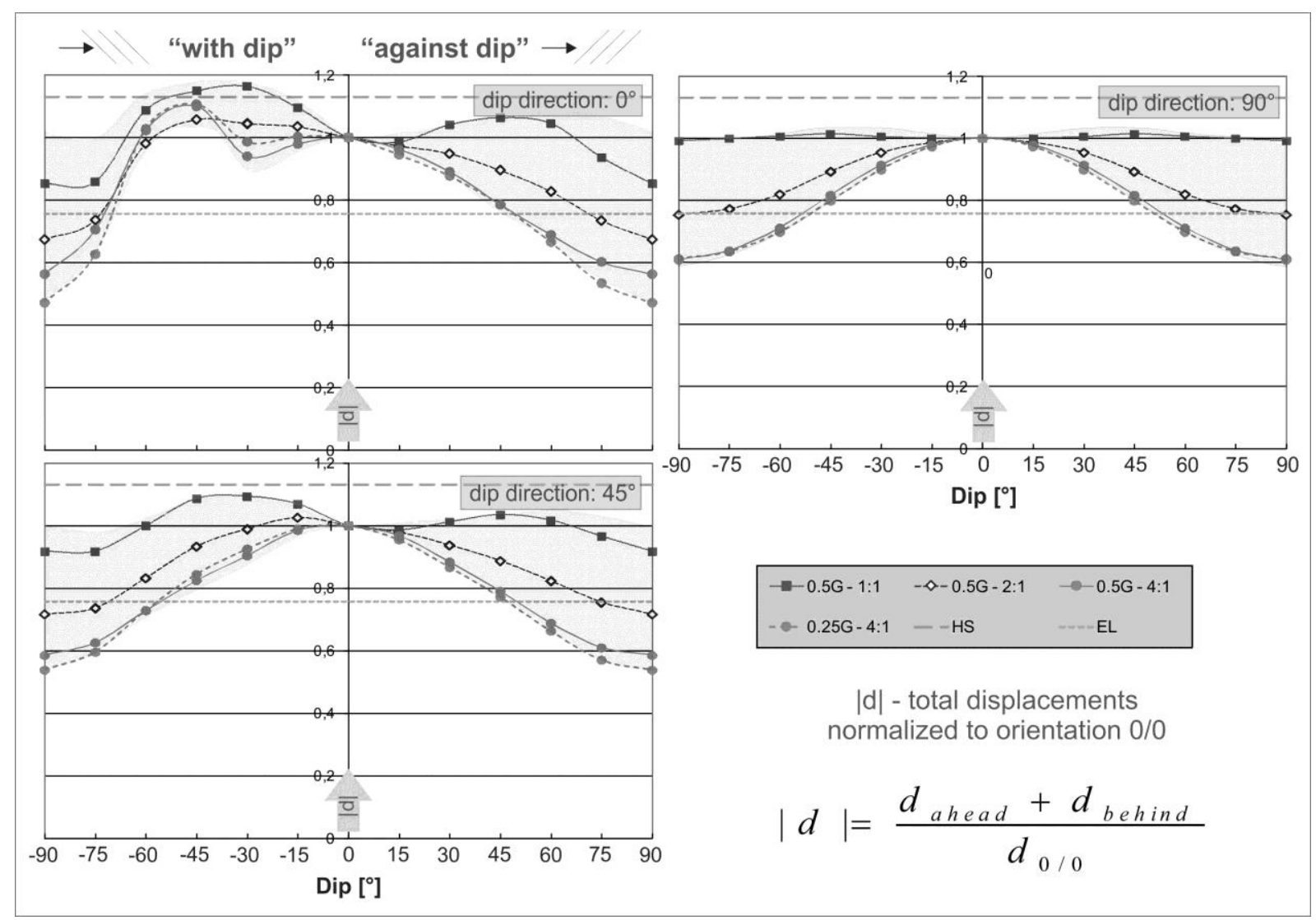

Fig. 4. Normalized total displacements of the tunnel crown point to total displacement of the same point at $0^{\circ} / 0^{\circ}$ for all combinations of $E_{1}: E_{2}$ ratios, shear moduli and dip directions.

\subsection{Proportion of displacements occurring behind tunnel face}

Only displacements that occur behind the tunnel face are routinely measured during tunnelling. Using the calculated values of $Q_{1}$ and $|d|$ from Fig. 2 and Fig. 4 we can define the normalized displacement behind the tunnel face as:

$Q_{2}^{*}=|d|\left(1-Q_{1}\right)$ 
Let us now observe the magnitude of normalized displacement behind the tunnel face when tunnelling in the same rock mass conditions with $\operatorname{dip} Q_{2 R}^{* W \mathrm{DD}}$ and against $\operatorname{dip} Q_{2 R}^{* \mathrm{AD}}$. In order to do so, the ratio

$\mathrm{Q}_{2 \mathrm{R}}^{*}=\frac{\mathrm{Q}_{2}^{* \mathrm{AD}}}{\mathrm{Q}_{2}^{* \mathrm{WD}}} \cdot 100 \%$

is plotted as a function of dip, dip direction, degree of anisotropy $\left(E_{1}: E_{2}\right)$ and shear modulus (Fig. 5). Only plots for dip directions $0^{\circ}$ and $45^{\circ}$ are presented, since there is no difference in the magnitude of displacements if tunnelling with or against dip at dip direction $90^{\circ}$ (symmetry of $|d|$ in Fig. 5 for dip direction $90^{\circ}$ ).

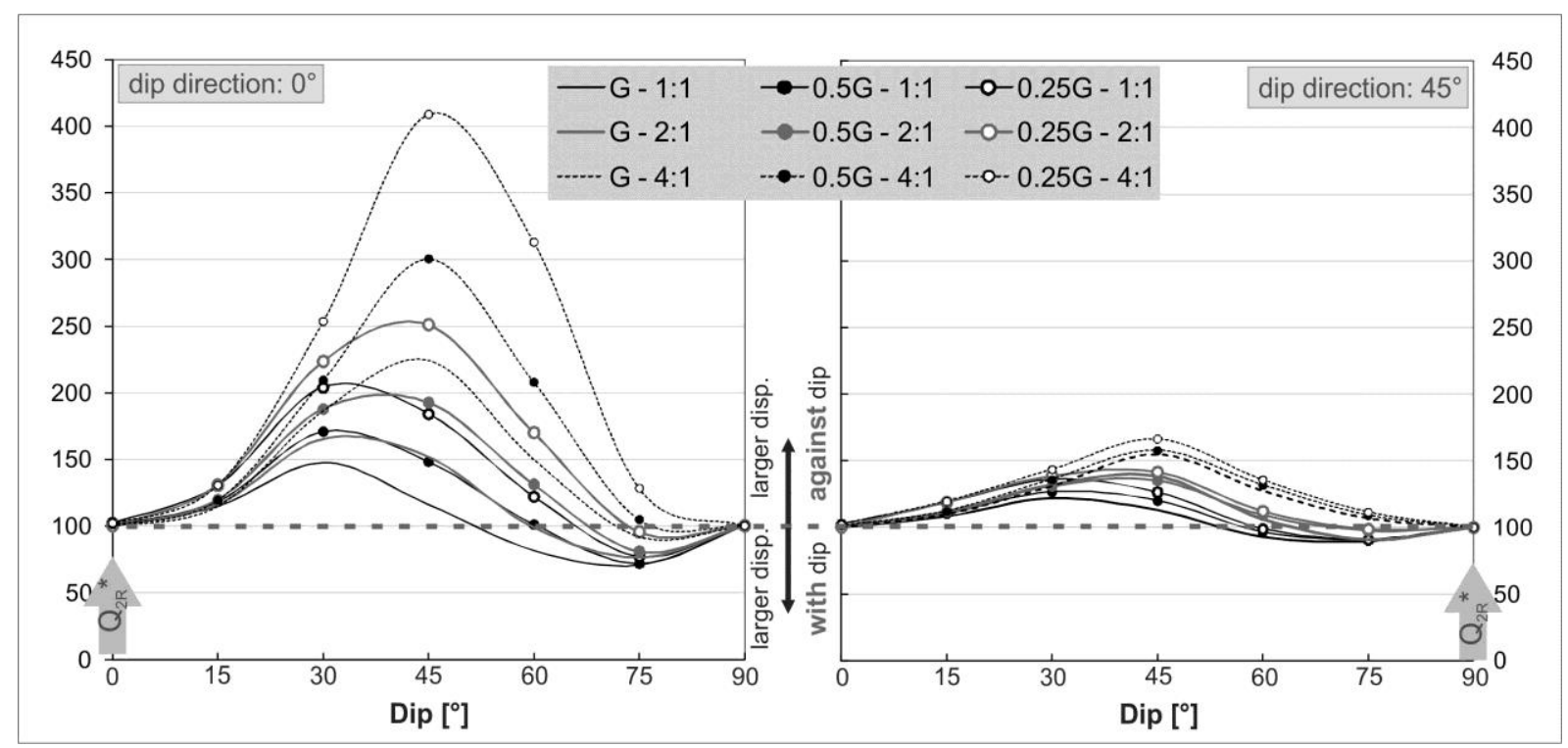

Fig. 5. Ratio $\left(Q_{2 R}^{*}\right)$ of the displacements occurring behind the face when tunnelling against dip and with dip.

For dip direction $0^{\circ} Q_{2 R}^{*}$ can be as high as $400 \%$ for $E_{1}: E_{2}=4: 1, G_{2}=0.25 G$ and dip angle $45^{\circ}$, as shown in the left graph of Fig. 5. In this case the measured displacement (i.e. the settlement of the crown point occurring behind the face) when tunnelling against dip would be 4 times the settlement of the same point if the tunnel was excavated from the other direction. The lower bound is defined by a curve for the ratio $E_{1}: E_{2}=1: 1$ and $G_{2}=G$ with the maximum ratio $Q_{2 R}^{*}=150 \%$ at a dip angle of $30^{\circ}$. For rock masses with lower degree of anisotropy, higher shear modulus $G_{2}$ and steep dip angles, $Q_{2 R}^{*}$ is lower than $100 \%$, which means that the settlement of the crown point when tunnelling against dip would be smaller than when tunnelling with dip. The decrease of the shear modulus causes proportional increase of $Q_{2 R}^{*}$, while the decrease of the $E_{1}: E_{2}$ ratio results in the increase of $Q_{2 R}^{*}$ and also in the shift of the curve maximum to the right, to steeper dip angles. The same observation stands also for the dip direction of $45^{\circ}$, only the magnitudes of $Q_{2 R}^{*}$ are considerably smaller (upper bound at $165 \%$, lower bound at $120 \%$ for moderate dip angles and $90 \%$ for steeper dip angles). 


\subsection{Variation of strength parameters}

The influence of variation of strength parameters (see Tab. 2) on the share of displacements occurring ahead of the tunnel face is shown in Fig. 6 . Curves in Fig. 6 represent the results obtained with the basic set of stiffness and strength parameters, while individual points and shaded areas show the extreme influence and range of values, respectively, for variations of strength parameters.

The influence of the variation of strength parameters is generally small when tunnelling against dip and when $G_{2}$ is small. The largest effect of the variation of strength parameters was observed for $G_{2}=G$ when tunnelling with dip. In extreme case $\left(E_{1}: E_{2}=4: 1,0.25 G_{2}\right.$ and the lowest strength properties $\varphi=12^{\circ}$, $c=15 \mathrm{kPa}), 95 \%$ of total displacement would occur ahead of the face $\left(Q_{1}=0.95\right)$.

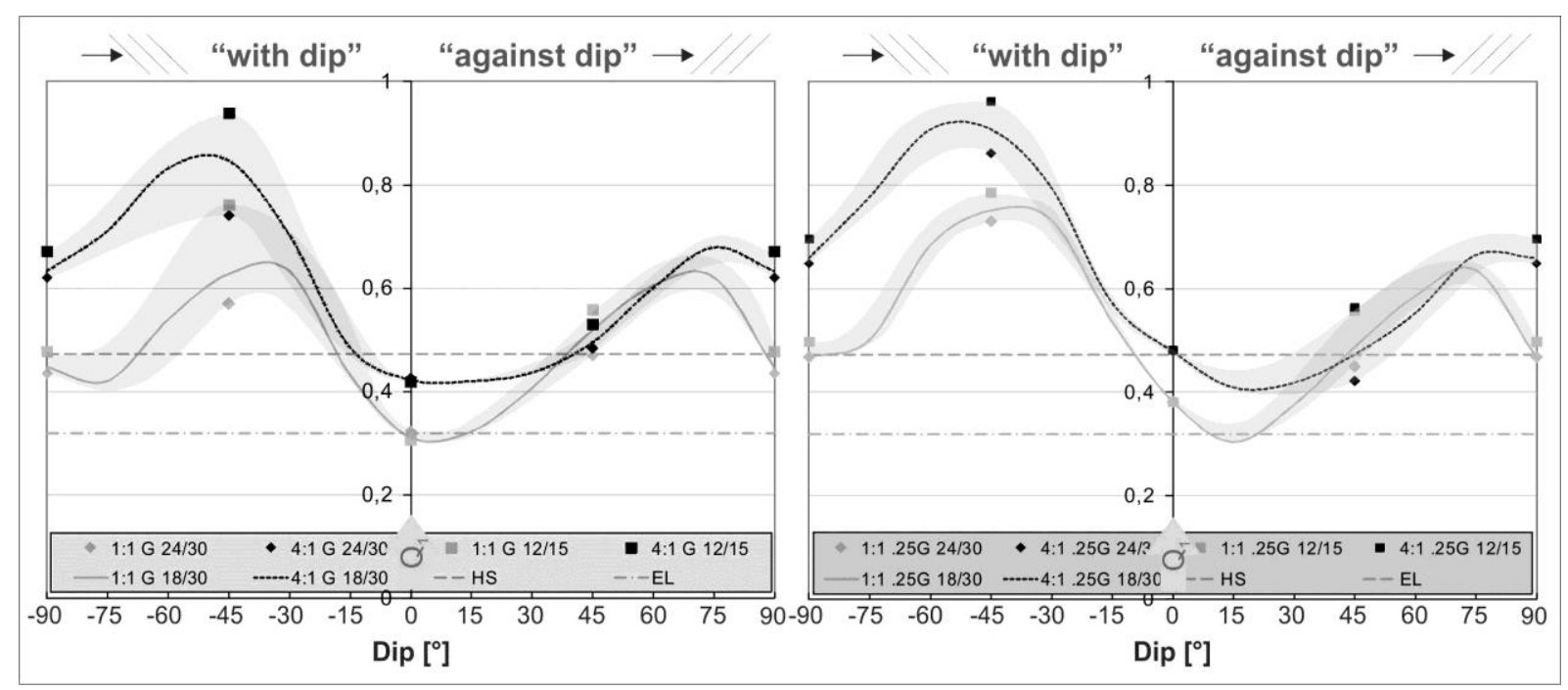

Fig. 6. Influence of variation of strength parameters on parameter $Q_{1}$. Left: $G_{2}=G$; right: $G_{2}=0.25 G$.

\subsection{The effect of lining stiffness and overburden on surface settlement}

Additionally, a series of numerical calculations varying lining stiffness and overburden height was performed for tunnelling with and against dip for dip direction $0^{\circ}$ and dip angle $45^{\circ}$. To investigate the influence of the lining stiffness, two values of elastic modulus were used (8 GPa and $80 \mathrm{GPa}$, referred to as normal and stiff lining, respectively), while the lining thickness was kept constant $(30 \mathrm{~cm})$.

Three different overburdens were considered $(25 \mathrm{~m}, 45 \mathrm{~m}$ and $100 \mathrm{~m})$. The length of the numerical model shown in Fig. 1 was extended to $250 \mathrm{~m}$, while for the $100 \mathrm{~m}$ overburden the model was adequately extended to $400 \mathrm{~m}$ to account for all the displacements due to tunnelling that are transferred to the tracked surface point in the middle of the model (distance $=0$ in Fig. 7).

Results for the highest considered degree of anisotropy $\left(E_{1}: E_{2}=4: 1\right.$ and $\left.0.25 G\right)$ are presented with normalized displacements in Fig. 7. Each curve in Fig. 7 presents the settlement of the observed surface point as a function of the relative tunnel face position. Thus, the last point of each curve corresponds to the final settlement after the tunnel has been completed.

It is interesting to note the difference in the share of surface settlement that occurs before the tunnel face passes beneath the observation point. For the overburden of $25 \mathrm{~m}$ and normal lining stiffness 
these values are $82 \%$ and $50 \%$ for excavation with and against dip, respectively. For the overburden of $100 \mathrm{~m}$, almost irrespective of the lining stiffness, $60 \%$ and $40 \%$ of surface displacements occur before the tunnel face passes beneath the observation point for tunnelling with and against dip, respectively.

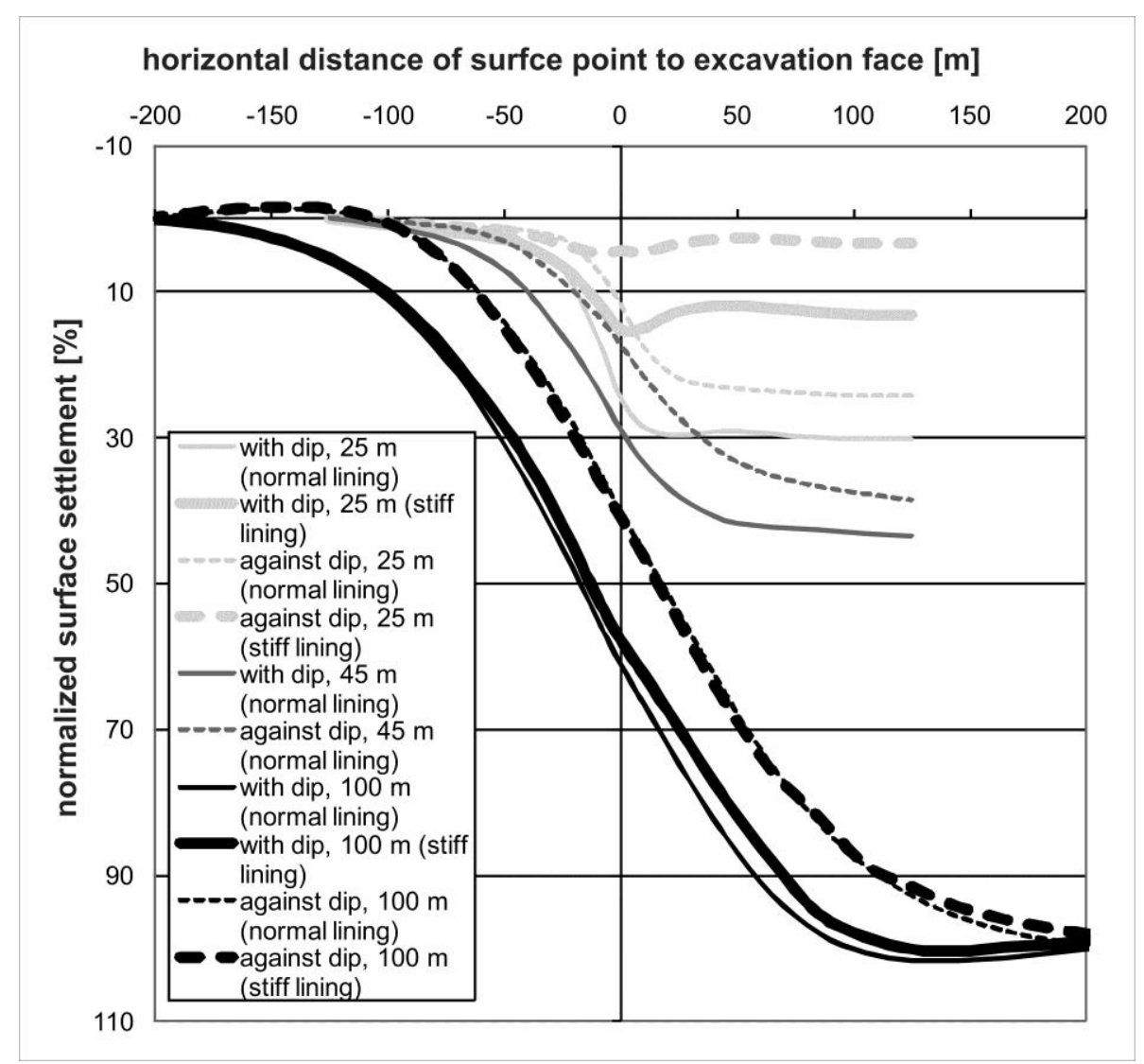

Fig. 7. Normalized settlement of the surface point (at distance $=0$ ) with respect to overburden and excavation direction regarding the relative anisotropy orientation (dip direction parallel to tunnel axis, $\operatorname{dip} 45^{\circ}, E_{1}: E_{2}=4: 1$ and $0.25 G$ ).

Let us observe the ratios of surface settlements when tunnelling with dip ( $\left.s_{\mathrm{WD}}\right)$ and against dip $\left(s_{\mathrm{AD}}\right)$. For soft lining, the $s_{\mathrm{WD}} / s_{\mathrm{AD}}$ ratio is $1.24,1.06$ and 1.00 for the overburdens of $25 \mathrm{~m}, 45 \mathrm{~m}$ and $100 \mathrm{~m}$, respectively. For stiff lining the $s_{\mathrm{WD}} / s_{\mathrm{AD}}$ ratio is still 1.00 for $100 \mathrm{~m}$ overburden, but reaches the value of 3.88 for the overburden of $25 \mathrm{~m}$. Therefore, the surface settlements can be influenced by the proper choice of excavation direction in combination with an adequate lining stiffness for shallow overburden. In case of stiff lining, uplift can be observed for both considered lining stiffnesses at an overburden of $25 \mathrm{~m}$ when tunnelling with dip after the passage of the excavation face. Stiffer lining results in more pronounced uplift with unrealistically large magnitude due to inability of the Jointed rock constitutive model to consider higher elastic modulus for unloading conditions.

However, no difference in the final settlement magnitude can be observed at $100 \mathrm{~m}$ overburden either for different lining stiffness and/or for the direction of tunnelling with regard to the discontinuity orientation. Due to high stress level at an overburden of $100 \mathrm{~m}$ the displacements are independent of 
the lining stiffness; therefore, also the courses of the displacement paths coincide. The only noticeable difference is in the courses of the displacement paths when tunnelling with or against dip.

When comparing the displacements occurring ahead of the face with those occurring behind the face in Fig. 7, one can conclude that the amount of the settlement that occurs prior to the passage of the excavation face beneath the observed point decreases with increasing overburden. The decrease is more pronounced for tunnelling with dip.

The final surface settlement increases considerably with overburden. Fig. 7 shows that for the overburden of $100 \mathrm{~m}$ it is approximately three times larger than for the overburden of 25 when tunnelling with dip and even four times higher when tunnelling against dip. The difference in settlements between the overburdens of 25 and $45 \mathrm{~m}$ is smaller but significant.

\subsection{Practical conclusion}

In the numerical analyses the settlements of the tunnel crown point and of the point at the surface were observed. The findings of the presented numerical calculations can be summarized with the following suggestion for practical applications:

If the tunnel is to be excavated with shallow overburden under populated area in highly anisotropic soft foliated rock mass with the discontinuity orientation that strikes perpendicular to the tunnel axis and with the dip angle of up to $60^{\circ}$, it would be more favourable to excavate it against dip, since the majority of the displacements would occur behind the face. These displacements could be partly controlled by stiff primary lining. In the opposite case (excavation against dip) the majority of the displacements would occur ahead of the face, where they are difficult to control and would unavoidably affect the infrastructure above.

If the tunnel was to be excavated in the same ground conditions under high overburden and/or under low overburden and green field conditions, it would be more favourable to excavate the tunnel with dip as the majority of the displacements would occur ahead of the face. The remaining displacements that occur behind the tunnel face are smaller, as are the lining forces.

The main reason for such behaviour is the anisotropic nature of the rock mass. The rock mass stiffness in the direction perpendicular to its structure (e.g. foliation) is usually smaller than the stiffness in the direction parallel to the structure. The anisotropy of the rock mass stiffness influences the displacement pattern directly and through the stress redistribution after the excavation of each round length of the tunnel.

\section{THE TROJANE TUNNEL CASE HISTORY}

The obtained numerical results could be verified with the measured displacements in tunnel sections close to the breakthrough, if they were executed in rather uniformly foliated or layered rock mass. Such breakthrough section with relatively uniform geological structure and sufficient length was identified in the Trojane tunnel. Further on, the presented numerical results enable to explain some 
other deformation patterns observed in the Trojane tunnel (Schubert et al [16]), such as large surface settlements despite stiff lining and fast ring closure as well as increasing surface settlements with increasing overburden.

\subsection{The Trojane tunnel}

The Trojane tunnel is a nearly $3 \mathrm{~km}$ long two-lane double tube motorway tunnel. Theoretical excavated cross section of the tunnel tube is $89 \mathrm{~m}^{2}$ with equivalent tunnel diameter of $10 \mathrm{~m}$. The overburden above the tunnel varies from $2 \mathrm{~m}$ up to $140 \mathrm{~m}$. The excavation proceeded from both portals in both tubes simultaneously. The tunnel alignment is situated in the rock mass of Carboniferous age and consists mainly of densely foliated soft claystone of dark grey to black colour; locally it includes lenses of stiffer grey siltstone and more competent lenses of sandstone. The rock mass is folded due to intensive tectonics (Schubert et al [16]). Several subvertical to vertical fault zones up to several meters thick were mapped, filled with low-bearing and highly deformable gouge clay. The general direction of the foliation is to the north-west, but can be locally chaotic due to tectonics. The foliation of the rock mass together with unfavourable dip angle of the layers affected the stability of the tunnel and the tunnelling conditions. The slopes above the tunnels are generally close to the limit equilibrium. These circumstances significantly influenced the tunnelling conditions under low overburden (eastern part). Consequently, the excavation affected the surface and existing nearby structures.

The tunnel was driven following the principles of NATM (Schubert et al [16]). The cross section excavation was performed in 3 steps: top heading, bench and invert. The opening was immediately supported by $30 \mathrm{~cm}$ thick reinforced shotcrete and radial rock bolts. The GSI values were being assessed continuously during tunnelling (Štimulak et al [17]). The majority of rock mass was assigned a GSI value between 20 and 25 with minimum and maximum value of 10 and 55 , respectively.

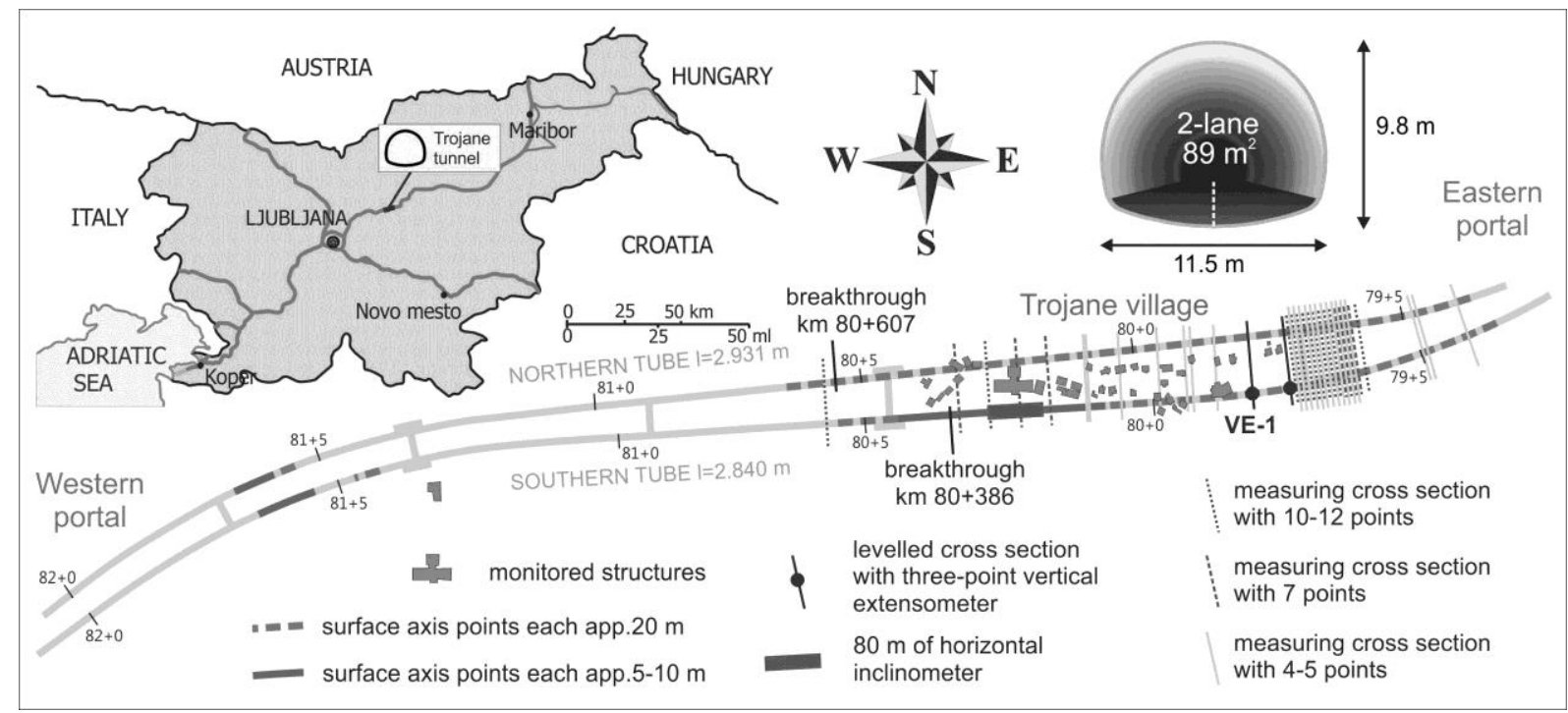

Fig. 8. General data and layout of the Trojane tunnel (Slovenia) with a scheme of surface monitoring. 
The most demanding part of the project was the tunnel construction under the Trojane village with low overburden from 10 to $25 \mathrm{~m}$. The eastern part of the tunnel (section of approximately $500 \mathrm{~m}$ ) was excavated under populated area, under main, regional and local roads and a regional gas pipeline. Therefore, an extensive monitoring programme (Fig. 8) was established (vertical inclinometers (Štimulak et al [18]), horizontal inclinometer above the tunnel crown (Volkmann et al [19]), 3D measurements of the surface geodetic points in cross sections and along the tunnel axis, vertical and horizontal multiple point extensometers, levelling of the structures in the influential area of the tunnel). To cope with demanding geotechnical conditions the 3D displacements of the primary lining were measured daily on 5 points in cross sections positioned every $14.5 \mathrm{~m}$ on average. Targets for 3D geodetic measurements were installed together with shotcrete lining immediately after the excavation of the last round length (typically 0.8 to $1.0 \mathrm{~m}$ long). The zero reading was normally taken within 6-10 hours after the excavation had been completed and before the beginning of the excavation of next round length.

\subsection{Breakthrough area of the northern tube of the Trojane tunnel}

The geological longitudinal section of the breakthrough area in the northern tube of the Trojane tunnel is presented in Fig. 12 along the tunnel axis. Note that the scale for the horizontal and vertical directions is not the same. To get the impression of the true angle of the dip of foliation, two $20 \mathrm{~m}$ long divisions were extracted and plotted beneath in true scale. The stereoplots in Fig. 12 show all available data along the $500 \mathrm{~m}$ long section, not only in the proximity of the tunnel axis but also along the sidewalls.

The rock mass in the western part consists mainly of siltstone alternating with beds of sandstone. GSI was in the range from 25 to 40 with an average value of 30 to 35 (line with dots in Fig. 12). In the eastern part siltstone alternates mainly with claystone and subordinately with sandstone. The average value of GSI was lower than in the western part (25 on average). Although some minor faults and local folds were mapped in the selected section, the geological structure can still be considered as sufficiently uniform. The tunnelling from eastern portal was performed with dip (dip angles of around $55^{\circ}$ ) and with dip direction towards the right sidewall, while the excavation from western portal proceeded with the same dip angle but against dip with dip direction towards the left sidewall.

Typical advance rate in the breakthrough area was $1.4 \mathrm{~m} /$ day for the excavation from east and 1.5 $\mathrm{m} /$ day for the excavation from west.

The measured displacements of approximately $120 \mathrm{~m}$ long sections from each heading are presented in Fig. 9 with the displacement vectors of three measurement points (one in the crown and two on each of the sidewalls in top heading) in longitudinal section. Although more favourable rock mass conditions were encountered when tunnelling from west as deduced from the GSI values, significantly larger displacements were generally observed in the western part.

In the section that was excavated from the western portal, the displacement vectors of the crown and the left side wall point explicitly into the excavation direction, while the displacement vector of the right sidewall point tends against the excavation direction. This phenomenon can be explained by the 
rotation of tunnel walls due to deformation perpendicular to the foliation (in this section predominant dip direction is around $60^{\circ}$ ). In the eastern part all displacement vectors point against the excavation direction.

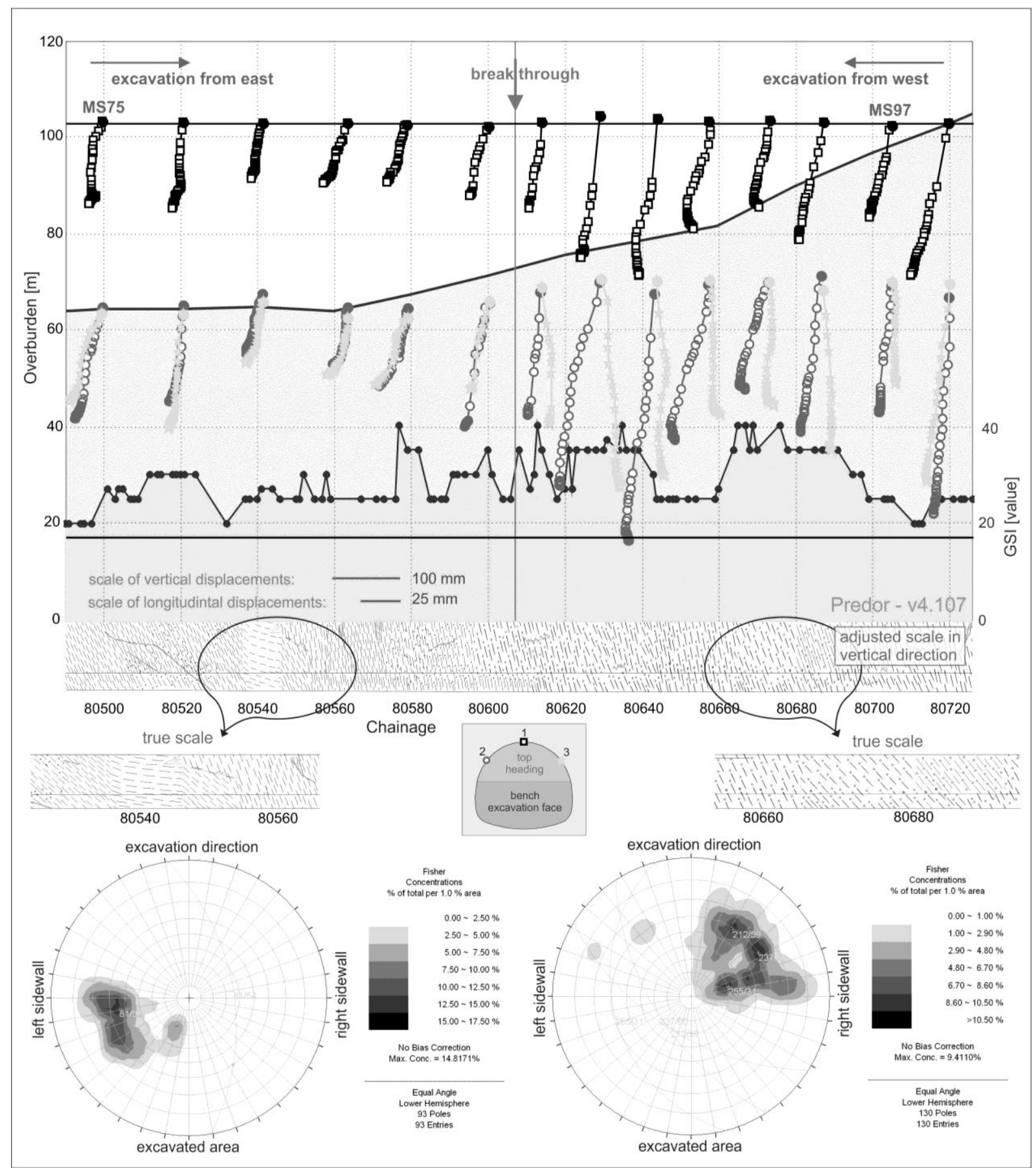

Fig. 9. Displacement vectors in the longitudinal section in the breakthrough area in the northern tube of the Trojane tunnel with lined geological longitudinal section (not in scale!) and the corresponding GSI value.

In the last 7 measuring cross sections (the closest measuring section to the breakthrough point in each of the lots is not taken into account) the ratio of average measured final displacement when 
tunnelling against dip compared to tunnelling with dip at the discussed section amounts to $197 \%$ for the crown points. No direct comparison with the calculated values of $Q_{2 R}^{*}$ (Fig. 5) is possible, since the real tunnel section is different from the numerical model in many aspects: overburden is not constant, dip and dip direction are not constant and do not correspond to 0 or $45^{\circ}$, degree of anisotropy is considerable but is not known. Taking into account the results for the dip direction of $45^{\circ}$, dip angle of $55^{\circ}, E_{1}: E_{2}=4: 1$ and $G_{2}=0.25 G$, one would expect the $Q_{2 R}^{*}$ value in the range of $150-160 \%$. If that value was calculated for the dip direction of 60 to $70^{\circ}$, the resulting $Q_{2 R}^{*}$ value would be smaller. On the other hand, if the changing overburden and higher degree of anisotropy were considered, the resulting $Q_{2 R}^{*}$ value would be larger. We can conclude, however, that there is strong empirical evidence that excavation direction in anisotropic rock mass influences the magnitude of tunnel displacements.

\subsubsection{Application of numerical results to displacement function}

The real value of the obtained results is revealed when individual measuring sections are analysed with the use of analytical displacement function, which was fitted to the measured displacements in the breakthrough area first using the $Q_{1}$ value from the literature $\left(Q_{1}=0.35\right.$, Sellner and Grossauer [20]) and then using the $Q_{1}$ value as obtained by numerical analyses for anisotropic rock mass. The output of the fitting procedure is shown in Fig. 10 for measuring section MS75 close to the breakthrough ( $\mathrm{km}$ $80+481$, tunnelling with dip from eastern portal). As the mapped relative dip direction in the vicinity of this measuring section is close to $45^{\circ}$ and the dip angle is around $50^{\circ}, Q_{1}=0.70$ was adopted and applied for the displacement function of both excavation phases (see Fig. 2 for $E_{1}: E_{2}=4: 1$ and $G_{2}=0.25 G$ ). The influential length ahead of the top heading face $x_{f}=15 \mathrm{~m}$ was also assessed on the basis of numerical results (Fig. 3). 


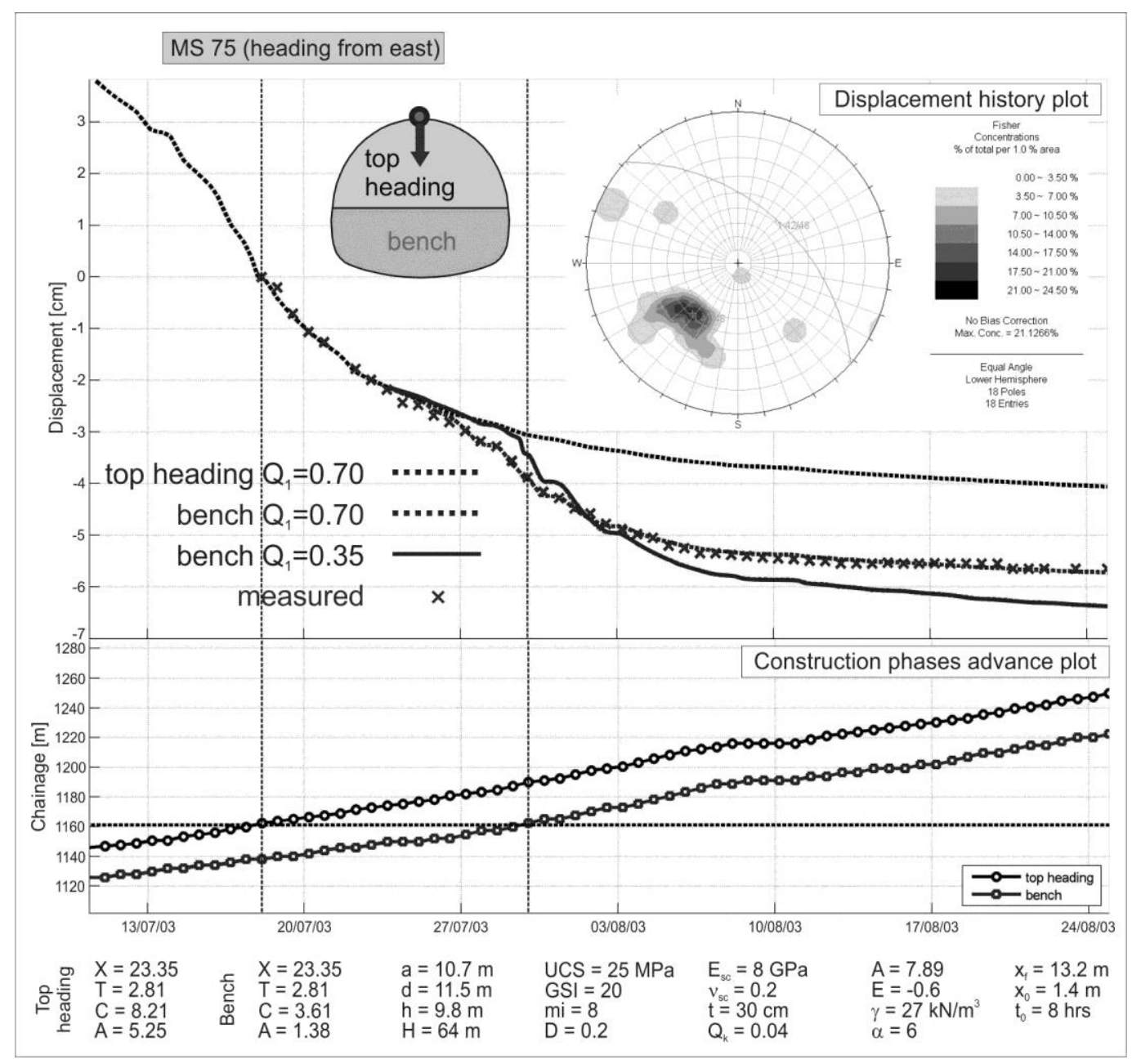

Fig.10. Fitted and monitored crown settlements of MS75 in the northern tube of the Trojane tunnel.

In Fig. 10 the measured settlement of the crown point is plotted with crosses and the fitted displacement function with solid line for $Q_{1}=0.35$ and with dashed line for $Q_{1}=0.70$, as obtained from numerical analyses.

The fitting procedure is first made on measured displacement after the excavation of the top heading. Displacement function for bench excavation phase is then obtained using the same shape parameters $X$ and $T$, as suggested by Sulem et al [9], and adjusting only parameters $C$ and $A$.

If $Q_{1}=0.35$ is applied, the displacement function cannot be satisfactorily fitted to the measured values with any combination of fitting parameters (solid line). With appropriate values of parameter $Q_{1}$ from numerical analyses a perfect fit was obtained, keeping the values of shape parameters $X$ and $T$ the same as obtained for the top heading excavation only. The matching of calculated and measured values for bench and invert is then obtained only by adjusting parameters $C$ and $A$. Moreover, for both measuring sections shape parameters $X$ and $T$ are the same.

Similar observations were made when fitting the displacement function to the measured displacements for other measuring sections. The use of parameters $Q_{1}$ and $x_{f}$ from Figs. 2 and 3 for suitable properties of anisotropic rock mass thus allows better approximation of the measured values with the displacement function and therefore enables the determination of more realistic values of fitting parameters for different rock mass types, which leads to more accurate displacement prediction. 


\subsection{Share of displacements occurring ahead of face in the Trojane tunnel}

The share of displacements occurring ahead of the tunnel face can be measured using several methods (vertical extensometers installed above the tunnel, horizontal inclinometers installed ahead of the tunnel, sliding micrometers) or indirectly assessed by convergence measurements in the pilot tunnel or comparison of tunnel and surface settlements. Monitoring programme in the eastern part of the Trojane tunnel below the Trojane village included some of these methods: vertical extensometer, 4 chains of horizontal inclinometer above the crown of the tunnel over an $80 \mathrm{~m}$ long section as well as geodetic monitoring of targets in the axis above the tunnel along a considerable length, as shown in Fig. 8. In this eastern part the tunnelling was performed predominantly with dip; dominant dip angle was around $20^{\circ}$, there was also large concentration of dip angles towards $30^{\circ}-35^{\circ}$ (stereoplot in Fig. 11). Typical excavation advance rate was $1.0 \mathrm{~m} /$ day, geodetic monitoring was performed regularly once a day.

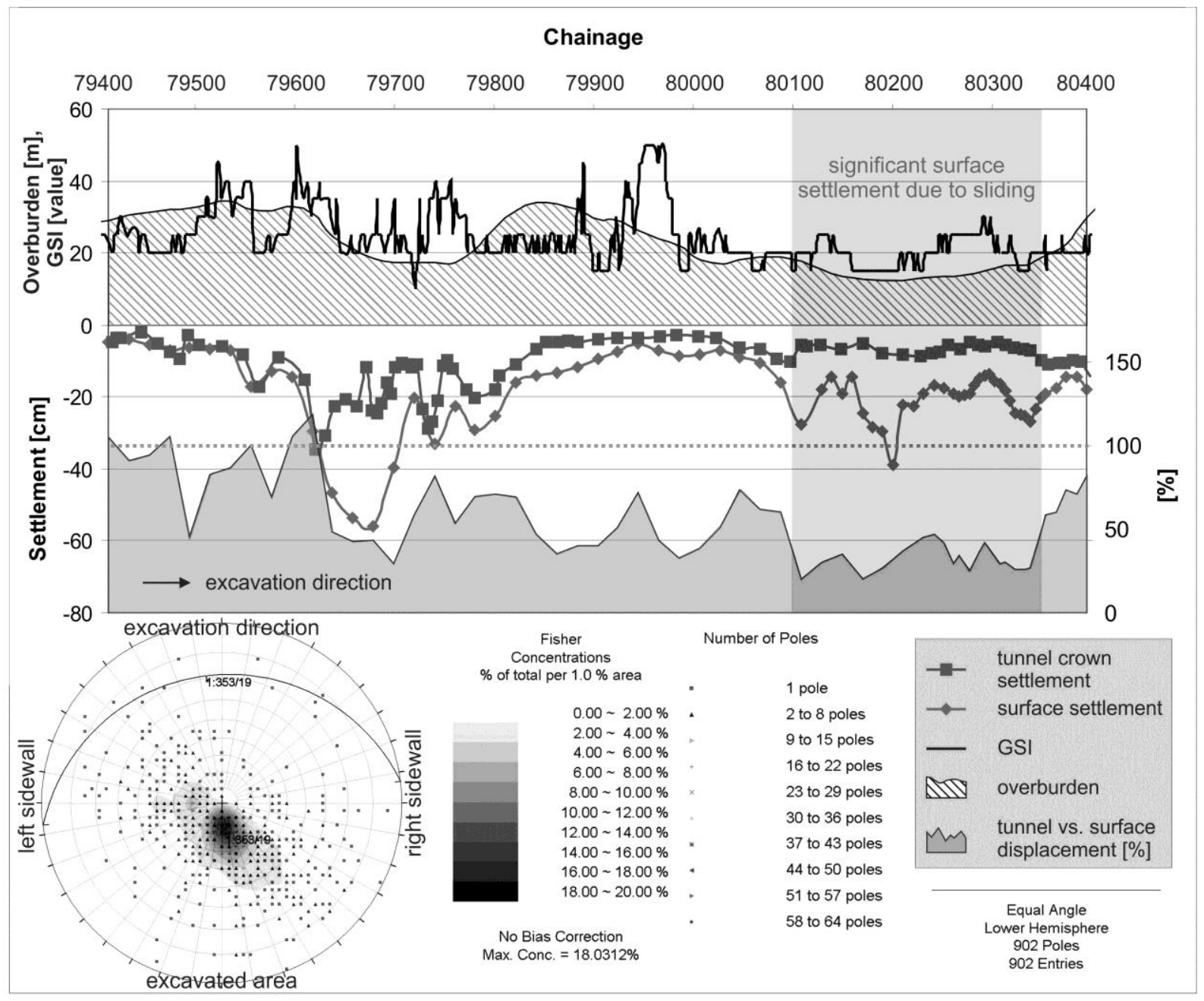

Fig. 11. Comparison between the final displacements of the tunnel crown in the southern tube of the Trojane tunnel (heading from eastern portal) and surface points above the axis of the tunnel; discontinuity orientations in this area (on the stereoplot) are plotted relative to the tunnel axis. 


\subsubsection{Comparison of tunnel and surface settlements}

When comparing final surface settlements (curve with square markers in the bottom graph of Fig. 11) and final settlements of the tunnel crown point (curve with diamond markers in the bottom graph of Fig. 11) in the eastern part of the southern tube of the Trojane tunnel, a large discrepancy between the measured tunnel and surface settlements can be observed. Although quite an effort was put into reducing the large influence of the tunnelling process onto the surface (installed pipe roof umbrella, long rock bolts ahead of the face with thick reinforced shotcrete cover of the face; the distance between top heading face and invert face was kept at a minimum), the majority of the settlements occurred ahead of the face, as shown in Fig. 11. In some places, only $1 / 3$ of the surface displacements were monitored in the tunnel. Generally, from chainage km 79+600 onwards the ratio of tunnel to surface settlement was in the range of $35 \%-80 \%$ (shaded area in the bottom plot of Fig. 11). Lower percentage generally corresponds to lower overburden above the tunnel (overburden is shown in the upper plot of Fig. 11). The ratio between the tunnel crown and the surface settlements did not change significantly even in better ground conditions with GSI of up to 50 .

During the tunnelling, a landslide occurred above the tunnel between $\mathrm{km} 80+100$ and 80+350 (see Fig. 11). The measured surface settlements within this section are only partly due to the tunnelling and partly due to sliding.

\subsubsection{Vertical multi-point extensometer}

The estimation of the volume loss that is transferred to the surface can be obtained by measuring settlements in different points in the rock mass above the tunnel, e.g. by multi-point vertical extensometers.

In the Trojane village a cross section of 7 points was installed on the surface at chainage $\mathrm{km} 79+842$, together with a three-point vertical extensometer in the axis of the future southern tube (denoted as VE-1 in Fig. 8). The surface target was placed $34 \mathrm{~m}$ above the tunnel crown. The three extensometer points were situated 4, 8 and $12 \mathrm{~m}$ above the crown, as shown in Fig. 12. Zero readings of all targets were recorded long before the influence of the tunnel could affect the area.

When the top heading face was approaching the measuring section, the positions of the points were taken once a week on average. When the tunnel face was in the close vicinity of the measuring section, the interval was reduced to daily measurements. The surface point reacted first, and the extensometer points followed with a minor time delay. When the tunnel surpassed the vertical extensometer, the measuring cross section was installed in the tunnel. All measurements continued until the rock mass was stabilized.

If the final tunnel crown settlement $(6.8 \mathrm{~cm})$ is compared to the final surface settlement $(13.8 \mathrm{~cm})$, the ratio is quite similar to the values from Fig. 11 (about 50\%). The extensometer anchor at the depth of $30 \mathrm{~m}$, which is $4 \mathrm{~m}$ above the crown, settled by $19.7 \mathrm{~cm}$ or three times the measured settlement of the tunnel crown. If we take the trend of the measured settlements of all three extensometer points (see Fig. 12) and extrapolate these values to the tunnel crown by taking into account that settlements 
increase in a nonlinear way closer to the opening, we can estimate the total settlement to around 25 $\mathrm{cm}$. In this case the final measured settlement of the crown presents only $27 \%$ of the final total settlement of the point in the tunnel crown due to tunnelling, if the complete deformation path was measured.

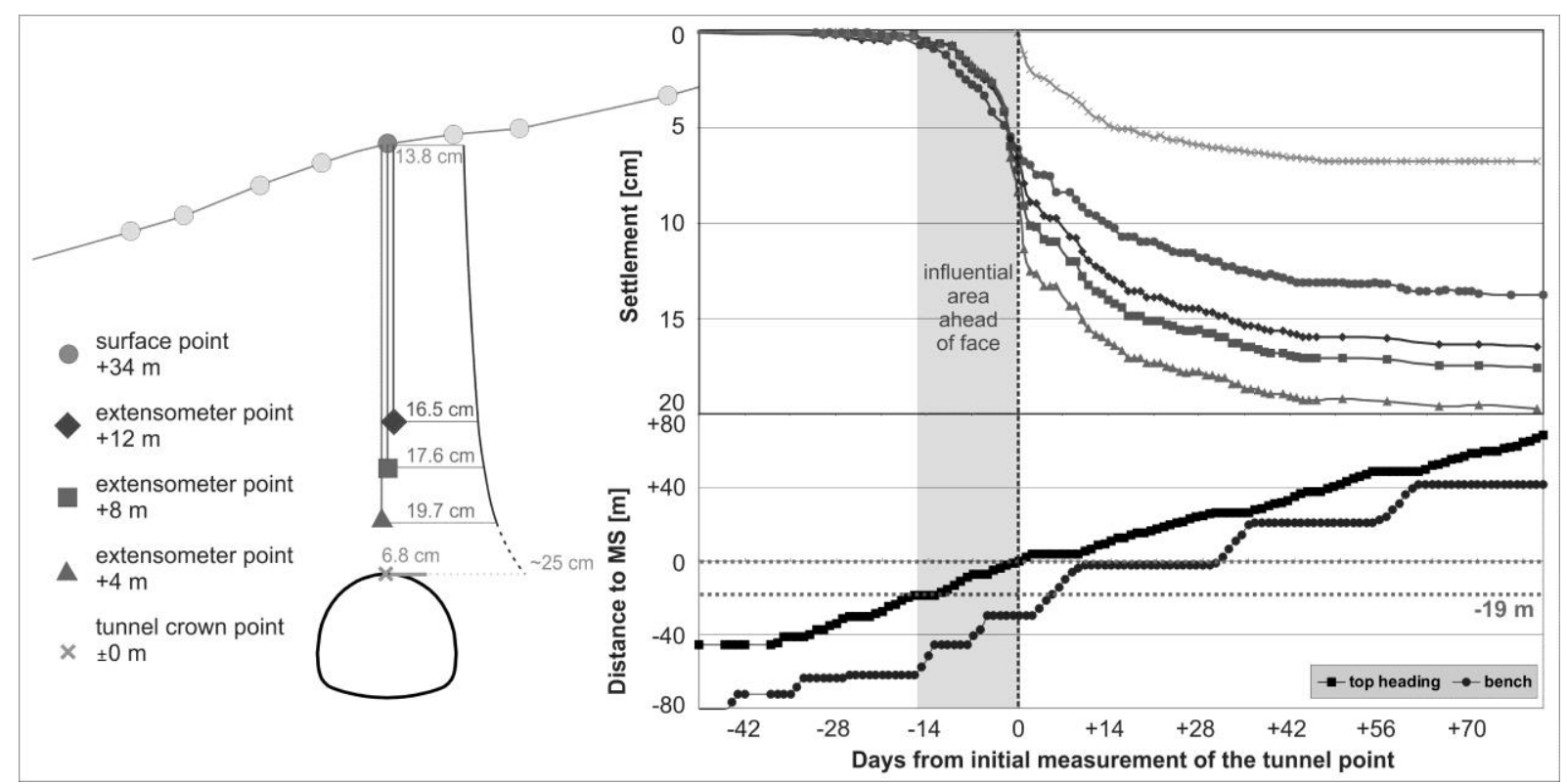

Fig. 12. Comparison of geodetically measured settlements of the tunnel crown and of the surface together with settlements of the rock mass in between, measured by a three-point vertical extensometer: the Trojane tunnel, southern tube, chainage km 79+842.

\subsubsection{Horizontal inclinometer}

Similar percentages were obtained when analysing the measurements taken by the horizontal inclinometer. To evaluate the effect of the pipe roof system, four $20 \mathrm{~m}$ long in-place horizontal chain inclinometers covering the total length of $80 \mathrm{~m}$ were installed in the southern tube of the Trojane tunnel, as shown in Fig. 8. Comparison of horizontal inclinometer readings and geodetically measured settlements of crown points also enables the assessment of the share of displacements that occur ahead of face. For 6 measuring sections positioned in this area the percentage of displacement behind the face was in the range from 24 to $37 \%$ (Tab. 3). 
Table 3. Comparison of final settlements of horizontal inclinometer and tunnel crown points in the southern tube of the Trojane tunnel (section between $\mathrm{km} 80+220$ and km 80+300).

\begin{tabular}{llll}
\hline MS No. & $\begin{array}{l}\text { Settlement of } \\
\text { horizontal } \\
\text { inclinometer }[\mathrm{mm}]\end{array}$ & $\begin{array}{l}\text { Settlement of } \\
\text { tunnel crown } \\
\text { point } \\
{[\mathrm{mm}]}\end{array}$ & $\begin{array}{l}\text { Percentage } \\
\text { of total } \\
\text { displacement [\%] }\end{array}$ \\
\hline 78 & 280 & 73 & 26 \\
80 & 180 & 67 & 37 \\
81 & 200 & 48 & 24 \\
82 & 190 & 54 & 28 \\
83 & 200 & 59 & 30 \\
84 & 200 & 48 & 24 \\
\hline
\end{tabular}

\subsubsection{Comparison with numerical results}

For dominant discontinuity orientation (stereoplot in Fig. 11), the share of displacements that occur ahead of the face according to numerical results (Fig. 2) amounts to $Q_{1}=65 \%$ for $E_{1}: E_{2}=4: 1$ and $G_{2}=0.25 G$. The observations described in sections 4.3 .2 and 4.3 .3 show that only 24 to $37 \%$ of the total settlement of crown point were measured in the tunnel. By simple subtraction the share of displacement occurring ahead of the face would be 63 to $76 \%$, which fits well with the numerically obtained value. However, some important aspects have to be considered:

(1) the presented share of calculated displacements ahead of face does not comprise the displacements that occur between the excavation of the round length and the first measurement of the measuring section;

(2) when comparing tunnel and surface settlements it is not likely that the whole deformation due to tunnelling is transferred to the surface, as it was seen from the results of vertical extensometer in Fig. 12;

(3) geological structure of the area cannot be characterized as uniformly foliated rock mass (see the dispersion of discontinuity orientations on stereoplot in Fig. 11). A large number of observed orientations have larger dip angles. If we take into consideration the dip angle of $30^{\circ}$, the share of displacements that occur ahead of the face amounts to $80 \%$ of the total displacement $\left(Q_{1}=0.80-\right.$ Fig. 2).

\subsection{Analysis of surface displacements above the Trojane tunnel}

Final measured settlements of surface points above the breakthrough area of both tubes were analysed in the light of the obtained numerical results. The portion of the measured settlement of surface points that occurred prior to the passage of the tunnel face beneath the tracked point is shown for the southern and northern tubes of the Trojane tunnel in Fig. 13 and Fig. 14, respectively. The 
tunnelling from east was performed predominantly with dip and the tunnelling from west predominantly against dip.

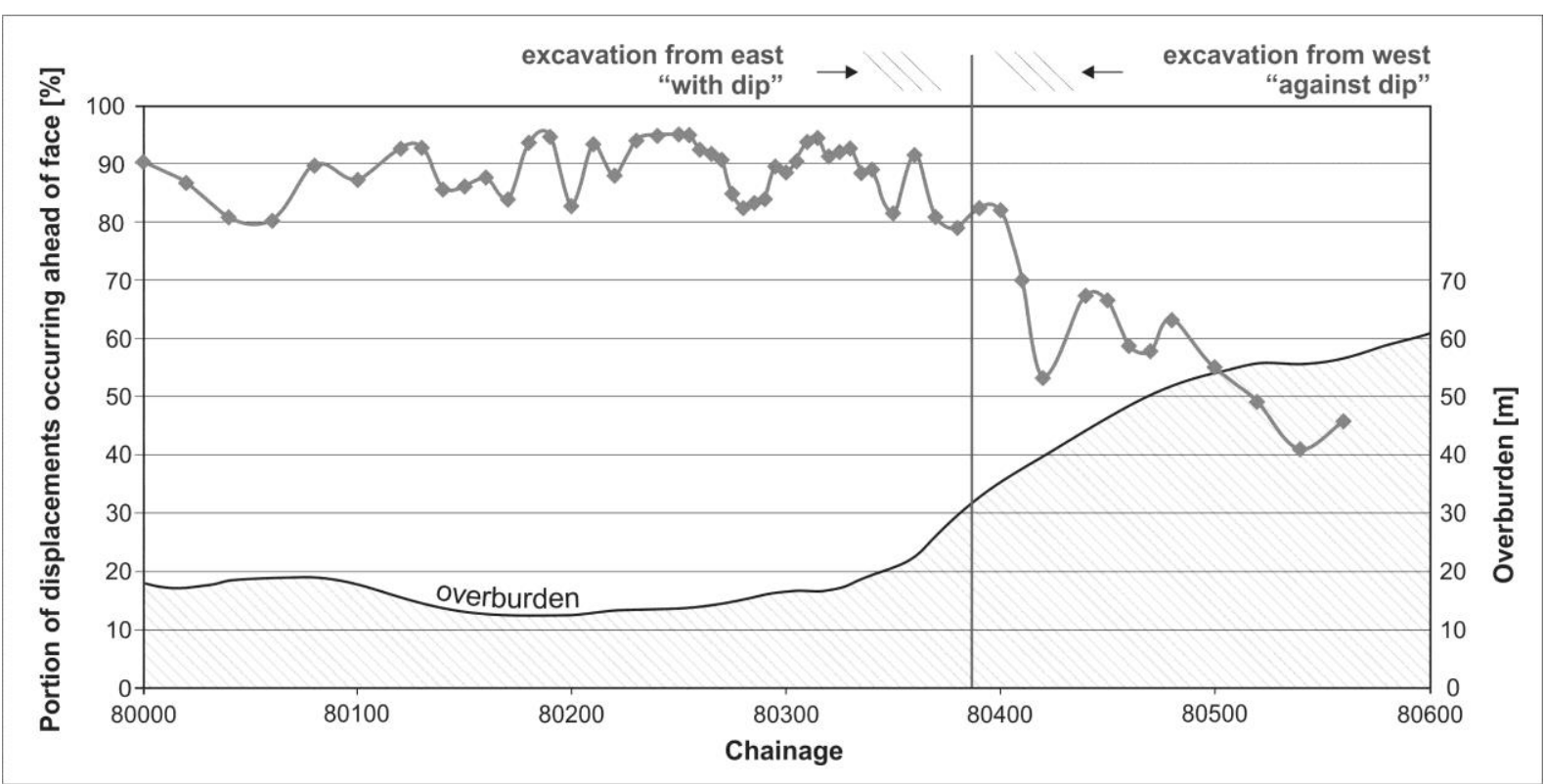

Fig. 13. Height of the overburden and portion of measured settlement of surface points that occurred prior to the passage of the tunnel face beneath the tracked point in the breakthrough area of the southern tube of the Trojane tunnel.

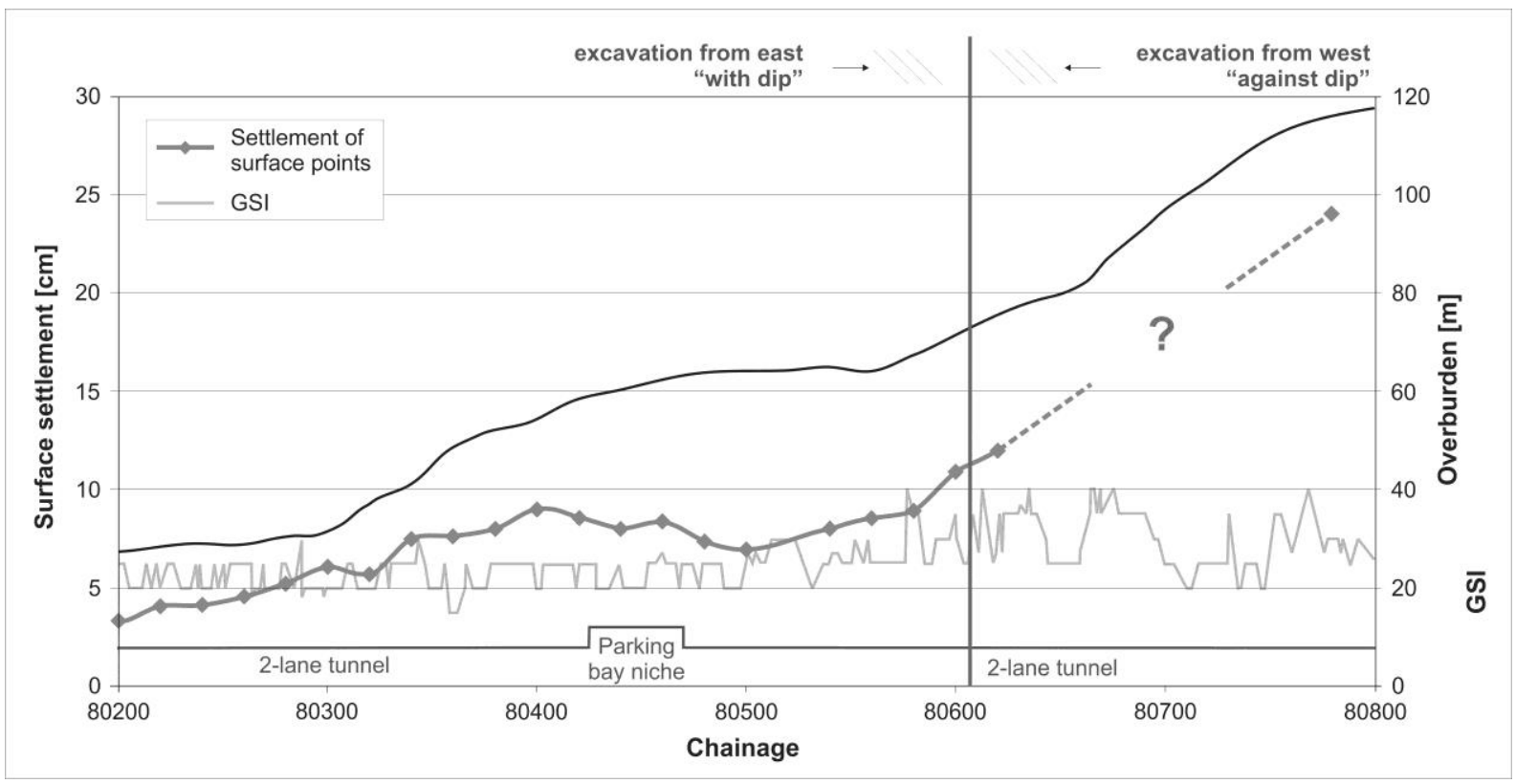

Fig. 14. Final settlement of surface points in the breakthrough area of the northern tube of the Trojane tunnel together with overburden and GSI.

In the southern tube, overburden above the eastern lot is rather constant, ranging between 12 and 20 $\mathrm{m}$, and it increases to $35 \mathrm{~m}$ at the breakthrough line, while overburden above the western lot decreases from 60 to $35 \mathrm{~m}$ at the breakthrough line. Excavation from east was stopped at the 
breakthrough line and the last $10 \mathrm{~m}$ were excavated from west. In the eastern part of the presented southern tunnel tube section, $80 \%$ to $95 \%$ of measured surface displacements occurred prior to the passage of the tunnel face and in the western part from $40 \%$ to $80 \%$. Significant part of surface displacement measured just west of breakthrough is actually the influence of excavation from east. Only for the most distant points where $40 \%$ to $50 \%$ of measured surface displacements occurred prior to the passage of the tunnel face we can assume that the influence from east is negligible. These field observations agree well with the numerical results shown in Fig. 7. For the overburden of $25 \mathrm{~m}$, the numerically obtained magnitude of the surface displacements occurring prior to the passage of tunnel face is $50 \%$ for tunnelling against dip and $82 \%$ for tunnelling with dip. For higher overburden and tunnelling against dip (western part) this share tends toward $40 \%$.

Overburden above the observed section of the northern tube increases from $25 \mathrm{~m}$ in the eastern part to roughly $120 \mathrm{~m}$ in the western part. The Trojane village is situated above the eastern part. Surface was monitored with geodetic targets installed each $20 \mathrm{~m}$ in the axis of the tunnel tube. Above the western part, only one measuring point was located on the regional pipeline at an overburden of 117 m.

As the overburden increases towards west, also the settlements of surface points increase from 3 to 5 $\mathrm{cm}$ at the overburden of $25 \mathrm{~m}$ to $7 \mathrm{~cm}$ at the overburden of $45 \mathrm{~m}$ and finally to $12 \mathrm{~cm}$ at the breakthrough line. The final measured settlement of the point at pipeline reached $24 \mathrm{~cm}$, although somewhat better geological conditions were encountered at the western part. Still, some displacement might have been missed due to late baseline measurement.

The calculated ratios of final surface settlements (Fig. 7) were as follows: $100 \%$ for $100 \mathrm{~m}$ overburden and excavation against dip, $32 \%$ for $45 \mathrm{~m}$ overburden and excavation with dip and $25 \%$ for $25 \mathrm{~m}$ overburden and tunnelling with dip. If $24 \mathrm{~cm}$ settlement is taken as a reference $100 \%$ value, $4 \mathrm{~cm}$ (at $25 \mathrm{~m}$ overburden) presents $17 \%$ and $7 \mathrm{~cm}$ (at $45 \mathrm{~m}$ overburden) $29 \%$ of reference settlement, which correspond fairly well with numerical results.

\section{CONCLUSION}

The presented findings based on extensive numerical study and supported by the case history of the Trojane tunnel indicate that rock mass displacements due to tunnelling in soft anisotropic rock formations largely depend on the relative orientation of the tunnel axis to strike and dip of anisotropy planes. Especially when tunnelling with dip, large portion of displacements occur ahead of the tunnel face. As a consequence, it is in such cases impossible to limit surface settlements by using stiff tunnel lining.

The results of numerical work are presented as share of displacements that occur ahead of tunnel face $\left(Q_{1}\right)$ and the influential length ahead of tunnel face $\left(x_{f}\right)$ that are also important parameters of displacement function. It was shown on the case of the Trojane tunnel that only by using the values of $Q_{1}$ and $x_{f}$ as obtained from anisotropic numerical models, perfect fit of displacement function to the measured displacement time history is possible.

Practical implication of the presented work can be summarized by the following recommendations: 
In case of anisotropic ground conditions, low overburden and populated area above the tunnel, the tunnel should be, if possible, driven against dip, since the majority of displacements due to tunnelling activities will occur behind the tunnel face and surface settlements can thus be reduced by stiff lining. In all other cases (low overburden but no infrastructure above, high overburden) it is more favourable to drive the tunnel with dip, since the majority of the displacements will occur ahead of the face, and the necessary amount of overexcavation as well as the loads transferred to the lining would thus be considerably smaller, which would result in more economic tunnelling.

The numerically obtained values were applied to the case of the Trojane tunnel and some interesting phenomena could be explained by these findings:

- large surface settlements despite quick ring closure, stiff lining and consequently small displacements of the tunnel lining,

- different magnitudes of measured displacements on the two sides of the breakthrough point in fairly similar rock mass conditions (even larger displacements were observed on the western side with slightly better rock mass),

- large surface settlement at high overburden was the result of the anisotropic nature of the rock mass.

To support the abovementioned findings, also the influence of the overburden on the magnitude of surface settlements was investigated. The findings were surprising. Instead of decreasing, settlements may increase with overburden, as also measured above the Trojane tunnel, which is again a consequence of rock mass anisotropy and relative orientation of the tunnelling to the rock mass discontinuities.

\section{REFERENCES}

[1] Wyllie DC. Foundations on rock. Chapman \& Hall; 1992.

[2] Wittke W. Rock mechanics. Springer-Verlag; 1990.

[3] Solak T. Ground behaviour evaluation for tunnels in blocky rock masses. Tunn. undergr. space technol. 2009;3:323-330. DOI:10.1016/j.tust.2008.10.004

[4] Huber G, Westermayr H, Alber O. Einfluss der Gefügeorientierung am Strenger Tunnel. Felsbau 2005;5:20-24.

[5] Goricki A, Button EA, Schubert W, Pötsch M, Leitner R. The influence of discontinuity orientation on the behaviour of tunnels. Felsbau 2005;5:12-18.

[6] Leitner R, Pötsch M; Schubert W. Aspects on the numerical modelling of rock mass anisotropy in tunnelling. Felsbau 2006;2:59-65.

[7] Tonon F, Amadei B. Effect of elastic anisotropy on tunnel wall displacements behind a tunnel face. Rock Mech. Rock Engng. 2002;3:141-160. 
[8] Sellner PJ. Prediction of displacements in tunneling. PhD thesis. Technische Universität Graz, Graz, Austria; 2000.

[9] Sulem J, Panet M, Guenot A. Closure analysis in deep tunnels. Int. J. Rock Mech. Min. Sci. 1987; 24:145-154.

[10] Barlow JP. Interpretation of tunnel convergence measurements. MSc thesis. Department of Civil Engineering, The University of Alberta, Edmonton, Alberta; 1986.

[11] Guenot A, Panet M, Sulem J. A new aspect in tunnel closure Interpretation. In: Proceedings of the 26th US Symposium on Rock Mechanics. Rapid City, USA; 1985. p. 445-460.

[12] Schubert W, Button EA, Sellner PJ, Solak T. Analysis of Time Dependent Displacements of Tunnels. Felsbau 2003;5:96-103.

[13] Klopčič J. Analysis and prediction of displacements for tunnels in foliated rock mass of Permcarboniferous age. PhD thesis. University of Ljubljana, Ljubljana, Slovenia; 2009. Available at http://drugg.fgg.uni-lj.si/3226/

[14] Likar J. Back analyses of time-dependent displacement at the Trojane tunnel construction, Acta Geotechnica Slovenica 2004;1:21-36. Available at http://www.fg.uni-mb.si/journalags/pdfs/AGS 2004 article 3.pdf (23.1.2013)

[15] Likar J, Vukadin V. Time-dependent back analysis of a multianchored pile retaining wall. J. Geotech Geoenviron Eng ASCE, 129 (2003); 1:91-95. DOI: 10.1061/(ASCE)10900241(2003)129:1(91)

[16] Schubert P, Klopčič J, Štimulak A, Ajdič I, Logar J. Analysis of characteristic deformation patterns at the Trojane tunnel in Slovenia. Felsbau 2005;5:25-30.

[17] Štimulak A, Ajdič I. Influence of the excavation of the Trojane tunnel on surface in the area of Trojane village, In: Proceedings of the 7th International Symposium on Tunnel Construction and Underground Structures. Ljubljana, Slovenia; 2004. p. 17-24.

[18] Štimulak A, Ajdič I. Damage risk assessment and geological-geotechnical monitoring of the MW tunnel in the area of Trojane village, In: Proceedings of the 6th International Symposium on Tunnel Construction and Underground Structures. Ljubljana, Slovenia; 2002. p. 81-94.

[19] Volkmann G, Schubert W. The use of horizontal inclinometers for the optimization of the rock mass - support interaction. In: Proceedings of the ITA World Tunnelling Congress. Istanbul, Turkey; 2005. p. 967-972.

[20] Sellner PJ, Grossauer K. Prediction of displacements for tunnels. Felsbau 2002;2:22-28. 